\title{
Impact of topography on earthquake static slip estimates
}

\author{
Leah Langer ${ }^{\mathrm{a}, * *}$, Théa Ragon ${ }^{\mathrm{b}, * *}$, Anthony Sladen $^{\mathrm{c}}$, Jeroen Tromp $^{\mathrm{a}, \mathrm{d}}$ \\ ${ }^{a}$ Department of Geosciences, Princeton University, USA \\ ${ }^{b}$ Seismological Laboratory, California Institute of Technology, 1200 E. California Blvd., Pasadena, CA 91125, \\ $U S A$ \\ ${ }^{c}$ Université Côte d'Azur, CNRS, IRD, OCA, Géoazur, 250 rue Albert Einstein, 06560 Valbonne, France \\ ${ }^{d}$ Program in Applied \& Computational Mathematics, Princeton University, USA
}

\begin{abstract}
Our understanding of earthquakes is limited by our knowledge, and our description, of the physics of the Earth. When solving for subsurface fault slip, it is common practice to assume minimum complexity for the Earth's characteristics such as topography, fault geometry and elastic properties. These characteristics are difficult to include in simulations and our knowledge of them is incomplete, leading many to believe that there is minimal advantage to be gained by accounting for these effects. However, 3D structure can be easily included with the newly-developed software package SPECFEM-X, and topography and bathymetry can be measured directly and are well known all over the Earth's surface. Accounting for topography thus seems to be an efficient strategy for incorporating accurate and extensive information into the inverse problem. Here, we explore the impact of topography on static slip estimates, with a particular focus on how topography may impact slip resolution on the fault. We also wonder if the influence of topography can be accounted for by simply using a receiver elevation correction. To this end, we analyze the $2015 \mathrm{M}_{\mathrm{w}} 7.5$ Gorkha, Nepal, and the $2010 \mathrm{M}_{\mathrm{w}} 8.8$ Maule, Chile, earthquakes within a Bayesian framework. The regions affected by these events represent two different types of topography. Chile, which contains both the Peru-Chile trench and the Andes mountains, has a greater elevation range and steeper gradients than Nepal, where the primary topographic feature is the Himalayan mountain range. Additionally, the slip of the continental Nepal event is well constrained, whereas observations are less informative in a subduction context. We show that topography has a non-negligible impact on inferred slip models. Our results suggest that the effect of topography on slip estimates increases with two main factors: poor observational constraints and high elevation gradients. In particular, we find that accounting for topography improves slip resolution where topographic gradients are large and the data is less informative: at depths for the Gorkha event, and near the trench for the Maule
\end{abstract}

\footnotetext{
${ }^{*}$ Equally contributing author, corresponding author

** Equally contributing author, corresponding author

Email addresses: llanger@princeton.edu (Leah Langer), tragon@caltech.edu (Théa Ragon)
} 
event. When topography has a significant impact on slip resolution, which is probably the case of many subduction events, the receiver elevation correction is not sufficient.

Keywords: Earthquake source observations, Inverse theory, Probability distributions, Mechanics, theory, and modelling, Maule earthquake, Gorkha earthquake, Nepal, Chile

\section{Introduction}

Estimates of subsurface fault slip are mainly constrained by observations of earthquake-induced deformation on the surface of the Earth, but they are also sensitive to information specified a priori to characterize the forward model. The forward model will always be an approximation to the real

5 Earth, and these approximations can affect inferences of fault slip (e.g., Beresnev, 2003; Hartzell et al., 2007). We often assume minimum complexity for the forward problem, partly because we are not certain about many detailed aspects of Earth structure, but also to simplify Green's functions computations. The simplest, and commonly used, description of the forward problem is a planar fault in a homogeneous elastic half-space with a flat surface. It is true that certain characteristics of the forward model, such as fault geometry and elastic heterogeneity, are often poorly known, but topography and bathymetry are well constrained at the global scale.

Synthetic tests have shown that topography of the free surface, within a simple configuration, can have a significant impact on predicted static surface deformation, particularly if the source is located at shallow depths (e.g., McTigue and Segall, 1988; Huang and Yeh, 1997; Williams and Wadge, 1998; Tinti and Armigliato, 2002). Within a realistic setup, several studies have found that Green's functions produced with a 3D model which includes topography and 3D elastic structure yield more accurate sub-surface fault slip estimates (e.g., Zhao et al., 2004; Moreno et al., 2012; Kyriakopoulos et al., 2013; Gallovič et al., 2015; Tung and Masterlark, 2016; Wang et al., 2017; Wang and Fialko, 2018). However, because most of these studies did not separate the effects of topography from those of heterogeneous elastic structure, it is not possible to determine the impact of topography alone from their results.

A few studies did examine the effect of topography on predicted surface deformation or estimated sub-surface fault slip. Most of those studies analyzed earthquakes in regions with relatively small topographic gradients, so the effects of topography were not found to be significant. Masterlark (2003) suggested that the effect of topography on both predicted surface displacements and inferred slip, within a subduction context, is negligible when compared to the impact of elastic heterogeneity. However, the earthquake used in that study was the $1995 \mathrm{M}_{\mathrm{w}}$ 8.0 Jalisco-Colisma earthquake in Mexico, where the topography gradient is of limited amplitude and confined near 
the trench. Similarly, Trasatti et al. (2011) showed that the addition of topography had a minimal effect on the slip distribution of the $2009 \mathrm{M}_{\mathrm{w}}$ 6.3 L'Aquila event in Italy due to the lack of strong topographic variations in the region. Williams and Wallace (2018) investigated shallow slow slip at the Hikurangi Subduction Margin in New Zealand, where the topography gradient is relatively smooth. They determined that accounting for topography would only yield a slight variation in their slip models (5\% difference in seismic potency), which is much smaller than the effect they 35 found for crustal heterogeneity ( $>50 \%$ difference in seismic potency). In contrast, Hsu et al. (2011) did examine the impact of topography on the predicted surface displacement for an earthquake that occurred in a region with significant topographic variations: the $2005 \mathrm{M}_{\mathrm{w}} 8.7$ Sumatra subduction event. They demonstrated than the effect of topography on predicted surface deformation can be significant, especially if the fault slip occurs close to areas with strong topographic gradients.

A previous study by some of these authors, Langer et al. (2019), found that the inclusion of topography has a significant effect on predicted surface deformation in a variety of settings. In particular, they modeled the 2015 Gorkha earthquake and found that 3D elastic structure and topography each caused differences of $10 \%$ in the predicted coseismic surface deformation. However, the differences due to topography were more significant because they affected the shape of the deformation pattern, not only its magnitude. In this study, we seek to build on those results by investigating the extent to which those differences in the predicted surface displacement pattern are mapped onto the inferred slip distribution.

Although previous studies have made some progress in investigating the impact of Green's functions with 3D structure on coseismic slip models, the effects of topography have not been thoroughly examined. Topography is very well known for every region in the world, and thus above any earthquake rupture, and yet its influence remains poorly investigated. Accounting for topography is a simple way to include accurate information about the Earth in our inverse problem. We wish to know whether the inclusion of topography improves resolution in estimated slip models.

An additional question that we wish to investigate is whether Green's functions with a receiver 55 elevation correction (REC), which can be computed easily, can reproduce the results found using Green's functions with topography. The receiver elevation correction is a method of accounting for the variations in distance between source and receiver caused by topography. This method was first explored by Williams and Wadge $(1998,2000)$ in a volcanic setting, and was implemented in a tectonic setting by some of these authors in Langer et al. (2019) and by Yang et al. (2019). However, the efficacy of the REC in a tectonic setting has not been determined.

In this study, we aim to analyze the impact of topography on static slip estimates. To this end, we base our analysis on the study of the $2015 \mathrm{M}_{\mathrm{w}} 7.5$ Gorkha, Nepal event and the 2010 

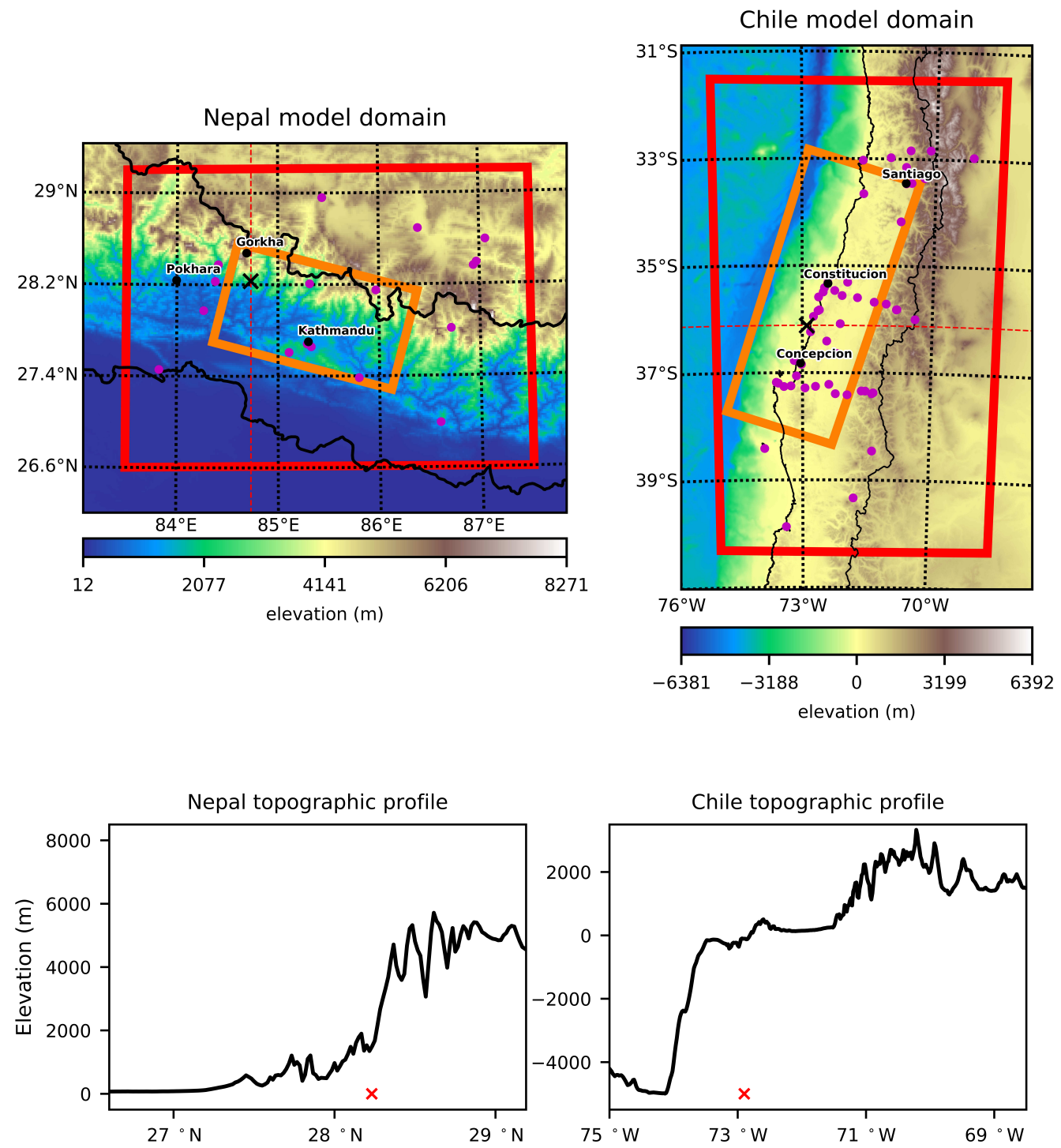

Figure 1: Topography of Nepal (left) and Chile (right). Red rectangles show the outlines of the meshes used to calculate Green's functions with topography for each of these regions. Orange rectangles show the outlines of the faults used in this study. Purple dots show the locations of the GPS stations. The black stars indicate the epicenters of the April 2015 Gorkha main shock and the February 2010 Maule main shock. Lower panels show topographic profiles for each region. The locations of the profiles are indicated by a red dashed line. Both profiles are near the epicenters of the two events, but the Nepal profile is north-south and the Chile profile is east-west so that the primary topographic features may be seen. 
$\mathrm{M}_{\mathrm{w}}$ 8.8 Maule, Chile event. These earthquakes were chosen because the regions of Nepal and Chile represent two end-members of topographic structure (Figure 1). Nepal's topography consists of many mountains and valleys that are close to one another, while Chile is segmented into large topographic domains: the trench and abyssal plain below $4000 \mathrm{~m}$, the margin and coastal plain around sea-level and the Andes mountain range mostly above $1500 \mathrm{~m}$ altitude. The two events also differ in their data coverage: while the Gorkha event occurred on a terrestrial fault that is well-constrained by numerous data covering the entire region of interest, the Maule earthquake is only constrained by data from the landward side of the fault.

For both events, we sample the possible slip parameters with a Bayesian approach, which allows us to thoroughly compare estimated slip models and to obtain detailed information on the posterior uncertainty of inferred parameters. We compare slip models estimated assuming Green's functions calculated with and without topography and with a first-order topographic correction. We first analyze these events within a synthetic framework and then using the real datasets. Note that our aim here is to investigate the impact of topography, not to produce the most realistic slip models of these events. We therefore make simple approximations for the other forward model parameters, such as fault geometry and elastic heterogeneity, to simplify our interpretations.

\section{Tools and methods}

\subsection{Generating 3D Green's functions}

A coseismic Green's function $G_{i j}$ is the displacement at a point $i$ on the surface of a domain due to slip on a subfault $j$. Green's functions for a particular region may be calculated by dividing the fault into subfaults and calculating the displacement on the surface of the domain due to a unit quantity of slip on each subfault. In our study, we do not constrain rake in the inversion, so we must calculate Green's functions for one meter of slip along strike and one meter of slip along dip. Thus, we must perform two calculations of surface displacement for each subfault.

To calculate Green's functions, we use a software package called SPECFEM-X (Gharti et al., 2019). SPECFEM-X, which is based on the spectral-infinite-element method, uses the (un)coupled elastic-gravitational equations to solve quasi-static problems. Since our Green's functions require only calculations of coseismic deformation, we can neglect gravity. The governing equations then become

$$
\nabla \cdot \mathbf{T}+\mathbf{f}=\mathbf{0} .
$$

Here, $\mathbf{T}$ is the incremental Lagrangian Cauchy stress and $\mathbf{f}$ represents external forces. 
There are several ways to implement a fault in SPECFEM-X. In this study, we use the momentdensity tensor fault implementation. Each subfault is subdivided into a grid of patches, and each 95 patch has an associated moment-density tensor given by (Dahlen and Tromp, 1998)

$$
\mathbf{m}=\Delta s \mathbf{C}: \hat{\mathbf{s}} \hat{\boldsymbol{\nu}}
$$

$\mathbf{C}$ is the elastic tensor at the location of the fault patch. $\mathbf{C}$ varies in a heterogeneous domain, but the models in this study are homogeneous, so for our purposes $\mathbf{C}$ is constant. $\hat{\boldsymbol{\nu}}$ is the normal vector and $\hat{s}$ is the slip direction. In general, these vectors must be calculated for each patch, but this study uses uniform fault geometry, so $\hat{\boldsymbol{\nu}}$ and $\hat{\boldsymbol{s}}$ do not vary between patches. $\Delta s$ is the slip magnitude. When calculating Green's functions, we set $\Delta s=1 \mathrm{~m}$.

SPECFEM-X calculates deformation throughout the mesh volume. However, we only need Green's functions at the locations on the surface where we have observations. The displacements at each of these observation points due to each fault patch are combined into a single matrix of Green's functions, $\mathbf{G}$.

\subsection{Receiver elevation correction}

Despite the efficiency of SPECFEM-X, we cannot match the speed of Green's functions calculations performed with the elastic half-space analytical solution (Steketee, 1958; Mansinha and Smylie, 1971). It would therefore be advantageous if there was a method of correcting the elastic half-space solution for topographic effects. There are two contributions to the topographic effect: the varying distance between the fault and the surface, and the elastic effects caused by the shape of the topographic surface (Williams and Wadge, 2000). The first of these effects can easily be accounted for by the receiver elevation correction (REC), in which all calculations are done with the elastic half-space approximation but, for each receiver, with a fault raised or lowered to preserve its absolute distance to the receiver position if topography had been there. A diagram of this method is shown in Figure 2.

The REC is very easy to implement and can be calculated quickly, since it requires only a slight modification to the standard homogeneous and elastic half-space calculation. However, it is not a good approximation when topographic gradients are steep in a volcanic setting (Williams and Wadge, 2000); in this case, a more complicated semi-analytical solution or FEM must be used. We wish to determine whether the REC is a good approximation for topography in slip inversions of the Gorkha and Maule events. To this end, we calculate Green's functions for these events with the receiver elevation correction, and perform inversions to determine whether the REC can recover the result found with topographic Green's functions calculated with SPECFEM-X. 


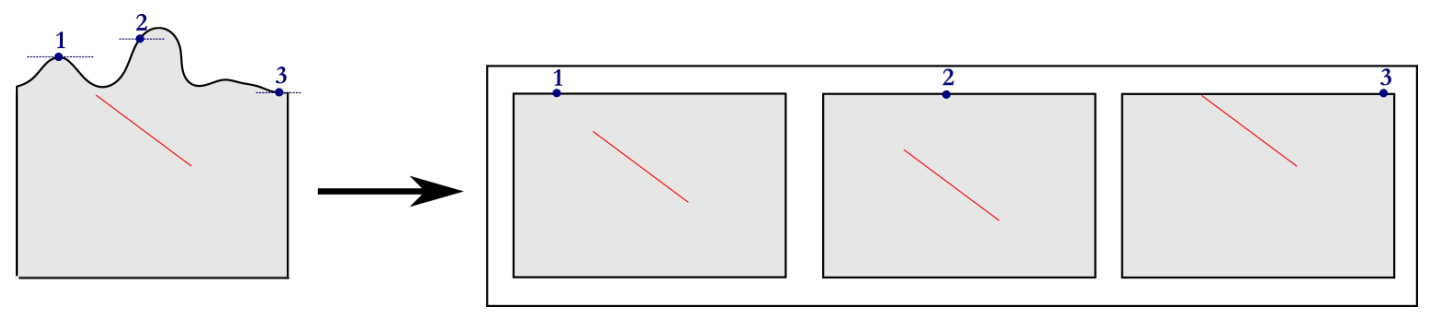

Figure 2: Green's functions with a receiver elevation correction are computed by calculating separate homogeneous half-space solution for each point on the surface where Green's functions are needed. We would like to raise the flat surface to the elevation of the desired point (left). Since this is not possible, we lower the fault instead so that the distance between the fault and the surface is correct (right). For each homogeneous half-space setup in the right-hand panel, the Green's function is only calculated at the blue point on the surface.

\subsection{Bayesian sampling}

Instead of trying to find a single solution to the inverse problem, we choose to sample the solution space and image a selection of its probable models. This sampling approach allows us to precisely compare various slip models and their posterior uncertainty. The approach is regularization free which, in our particular case, will allow to more precisely quantify the effects of topography. We use the Bayesian sampling approach implemented in the AlTar package (https://github.com/AlTarFramework/altar), which is a rewrite of the code CATMIP (Minson et al., 2013). AlTar combines the Metropolis algorithm with a tempering process to perform an iterative sampling of the solution space of source models. A large number of samples are tested in parallel at each transitional step. Additionally, resampling is performed at the end of each step to replace less probable models. The probability that a given sample will be selected depends on its ability to fit the observations $\mathbf{d}_{\text {obs }}$ within the uncertainties $\mathbf{C}_{\chi}=\mathbf{C}_{\mathrm{d}}+\mathbf{C}_{\mathrm{p}}$, where $\mathbf{C}_{\mathrm{d}}$ represents the observational errors and $\mathbf{C}_{\mathrm{p}}$ the epistemic uncertainties introduced by approximations of the forward model (e.g., Minson et al., 2013; Duputel et al., 2014; Ragon et al., 2018, 2019b).

The ability of each model parameter to solve the source problem is evaluated through repeated updates of the Probability Density Functions (PDFs):

$$
f\left(\mathbf{m}, \beta_{i}\right) \propto p(\mathbf{m}) \cdot \exp \left[-\beta_{i} \cdot \chi(\mathbf{m})\right],
$$

where $\mathbf{m}$ is the current sample, $p(\mathbf{m})$ is the prior distribution on this sample, $i$ corresponds to the current iteration and $\beta$ evolves dynamically from 0 to 1 to ensure an exhaustive exploration of the solution space (Minson et al., 2013). $\chi(\mathbf{m})$ is the misfit function:

$$
\chi(\mathbf{m})=\frac{1}{2}\left[\mathbf{d}_{\mathrm{obs}}-\mathbf{G} \cdot \mathbf{m}\right]^{T} \cdot \mathbf{C}_{\chi}^{-1} \cdot\left[\mathbf{d}_{\mathrm{obs}}-\mathbf{G} \cdot \mathbf{m}\right] .
$$


The impact of different approaches to regularization, along with the ad-hoc choice of smoothing parameters, may bias or induce unwanted artifacts in inferred slip models (e.g., Du et al., 1992; with a few exceptions. Tung and Masterlark (2016) calculated Green's functions for the Gorkha event using a finite element model with heterogeneous crustal structure and realistic topography, and used those Green's functions to invert for a slip model using GPS and InSAR data. The 
homogeneous elastic structure. They found that the heterogeneous Green's functions yielded a slip model that fits their data better. However, they did not investigate the impact of topography. Similarly, Wang et al. (2017) compared slip models recovered using Green's functions calculated in a homogeneous half-space and in a heterogeneous, topographic domain. The two models had slightly different slip distributions and different slip amplitudes. However, their tests showed that the dominant effect was likely due to the heterogeneous elastic structure, which makes it difficult to determine the impact of topography in isolation. A study on the effects of topography was performed by Yang et al. (2019), which computed Green's functions with and without the receiver elevation correction. They found that the two resulting slip models differed in both slip amplitude the coseismic deformation is unusually well constrained. This exceptional slip resolution explains why the published slip models are almost all identical. With this in mind, we might ask whether the inclusion of topography is necessary to improve our slip models or the fit to our data. To answer this question, we invert for synthetic slip models to determine whether Green's functions with topography can truly improve inversion results.

The unusually high constraint on the slip distribution of the Gorkha event is not shared by most earthquakes, especially subduction events, which occur in areas with strong topographic gradients that are far from any terrestrial data. It is conceivable that the impact of topography may not be noticeable with lower slip resolution. We therefore also investigate the Gorkha event using only

\subsection{Data and Forward Model}

\subsubsection{Data}

Our geodetic data set contains static co-seismic offsets from 18 3-component continuous GPS stations and 4 SAR interferograms. The data points are scattered over our model domain. The GPS offsets were provided by Galetzka et al. (2015) and Yadav et al. (2017). One Sentinel-1 ascending frame was used, collected by the European Space Agency and processed by Grandin et al. (2015). Two ALOS-2 descending frames and one ALOS-2 ascending frame, collected by the Japan 
Aerospace Exploration Agency (JAXA), were processed by Lindsey et al. (2015). The InSAR data have been downsampled based on model resolution (Lohman and Simons, 2005), and the data errors have been calculated following Jolivet et al. (2012). A more detailed description of our data can be found in Section S1 of the Supplementary Material. Note that the surface displacements derived from the InSAR data contain between 8 and 9 days of post-seismic deformation, and that our GPS displacements are daily solutions, which might affect our modeling of the coseismic phase (e.g. Ragon et al., 2019a; Twardzik et al., 2019)

\subsubsection{Crustal domain parameters}

Our model domain extends from $83.5^{\circ} \mathrm{E}$ to $87.5^{\circ} \mathrm{E}$ and $26.6^{\circ} \mathrm{N}$ to $29.2^{\circ} \mathrm{N}$. The mesh, shown in Figure S2, measures approximately $390 \times 280 \times 83 \mathrm{~km}$ and has a mesh spacing of $3 \mathrm{~km}$, for a total of 323830 elements. The mesh runs on 40 processors in approximately 5.2 minutes. The model domain has a Poisson's ratio of 0.25 and Young's modulus of $82.4 \mathrm{GPa}$. These are the material properties used for the homogeneous model of Nepal in Langer et al. (2019).

Our benchmarks, shown in Figure S3, showed that solutions produced by SPECFEM-X with a flat mesh are nearly identical to those produced with homogeneous and elastic half-space solutions (Okada, 1992) for coseismic deformation in a homogeneous half-space. Since homogeneous half-space calculations are much faster, we generated the Green's functions without topography using the analytical solutions. We choose to put the surface of the flat domain for the non-topography Green's functions calculations at an elevation of $244 \mathrm{~m}$, which corresponds to the elevation of the deepest point on the hinge line where the fault meets the surface in the topographic mesh.

\subsubsection{Assumed MHT fault geometry}

Many attempts have been made to determine the structure of the Main Himalayan Thrust (MHT) fault in Nepal. Some studies have found evidence that the MHT has a ramp-flat-ramp structure (Nábělek et al., 2009; Wang and Fialko, 2015; Elliott et al., 2016; Wang et al., 2017; Almeida et al., 2018b). A recent study using aftershock data from the Gorkha earthquake argued that instead of a lower ramp, the MHT has a duplex system of steeply dipping faults (Mendoza et al., 2019). Others have found that a planar fault provides the best fit to the data for the 2015 Gorkha earthquake (Whipple et al., 2016; Wang and Fialko, 2018). Even if a ramp-flat-ramp structure does exist in the region of interest, it probably would not have a significant effect on our inversion because nearly all studies agree that the vast majority of slip took place on the flat section of the fault (Elliott et al., 2016; Wang and Fialko, 2018; Yang et al., 2019). Therefore, we have chosen to use a planar fault when generating Green's functions, and we account for uncertainty in 
We assume a $180 \mathrm{~km}$ long and $100 \mathrm{~km}$ wide planar fault, with a strike of $285^{\circ}$ and a dip of $7^{\circ}$ northeast. Because the slip that occurred during this event did not reach the surface, we eliminated the upper section of the fault, so that the starting depth of the fault is at $3.9 \mathrm{~km}$. For the inversions with the complete dataset, the fault is divided into a grid of $10 \mathrm{~km} \times 10 \mathrm{~km}$ subfaults, so that there are 18 subfaults along strike and 10 subfaults along dip. When calculating Green's functions with topography using SPECFEM-X, we use 400 moment-density tensor patches for each subfault.

When only GPS data are used, the slip resolution is less. Therefore, we increase the size of each subfault to $15 \mathrm{~km} \times 12.5 \mathrm{~km}$. The fault has only 12 subfaults along strike and 8 subfaults along dip. When calculating Green's functions with topography using SPECFEM-X, we use 9216 momentdensity tensor patches for each subfault. The other fault parameters are detailed in Table 3 of the Supplementary Material.

\subsubsection{Other assumed prior information}

We perform our static slip estimation as previously detailed in Section 2.3. We specify a zeromean Gaussian prior $p(\mathbf{m})=\mathcal{N}(-1 \mathrm{~m}, 1 \mathrm{~m})$ on the strike-slip component, since we assume that, on average, the slip direction is along dip. For the dip-slip component, we consider each possible value of displacement equally likely if it is positive and does not exceed $25 \mathrm{~m}$ of normal slip: $p(\mathbf{m})=\mathcal{U}(0 \mathrm{~m}, 25 \mathrm{~m})$. We account for the data uncertainties as detailed in Section $\mathrm{S} 1$ of the Supplementary Material. We assume conservative uncertainty values of $\left(-2^{\circ} ; 2^{\circ}\right)$ around the prior value for the fault dip and $(-2 \mathrm{~km} ; 2 \mathrm{~km})$ for the fault position.

\subsection{Results}

We first wish to investigate the impact of topography on slip models without contamination from potential uncertainties or bias that may result from our choices of crustal properties and fault structure, or from data errors. Therefore, we will start by analyzing the results of synthetic tests. This will allow us to determine whether Green's functions with topography can truly improve the inferred slip distribution. We will then use our inversion procedure to estimate slip models using real data from the Gorkha earthquake. In both cases, we will perform inversions using two datasets, one consisting of all data points from GPS and InSAR, and one with GPS stations only.

\subsubsection{Synthetic tests}

For the synthetic inversions with the full dataset, our target model, shown in Figure 3A, consists of five pure dip-slip patches of $6 \mathrm{~m}$ amplitude: four $20 \times 20 \mathrm{~km}$ patches located at each corner of the fault, and a central patch $50 \mathrm{~km}$ long and $20 \mathrm{~km}$ wide. In the GPS-only case, shown in Figure $3 \mathrm{E}$, the corner slip patches are $30 \mathrm{~km}$ long and $25 \mathrm{~km}$ wide, and the central slip patch is $60 \mathrm{~km}$ long 
and $25 \mathrm{~km}$ wide. Using a topographic domain and the fault geometry specified in Section 3.1.3, we compute the surface displacements induced by each of these target models at the data locations. (around $29^{\circ} \mathrm{N}$, Fig
the synthetic data.

These synthetic tests show that the use of Green's functions with topography leads to a significant improvement in the recovered slip models. This is particularly true when the slip is not well-constrained due to poor data resolution since, in this case, use of non-topographic Green's functions leads to very poor estimates of the slip distribution. Green's functions with the receiver 

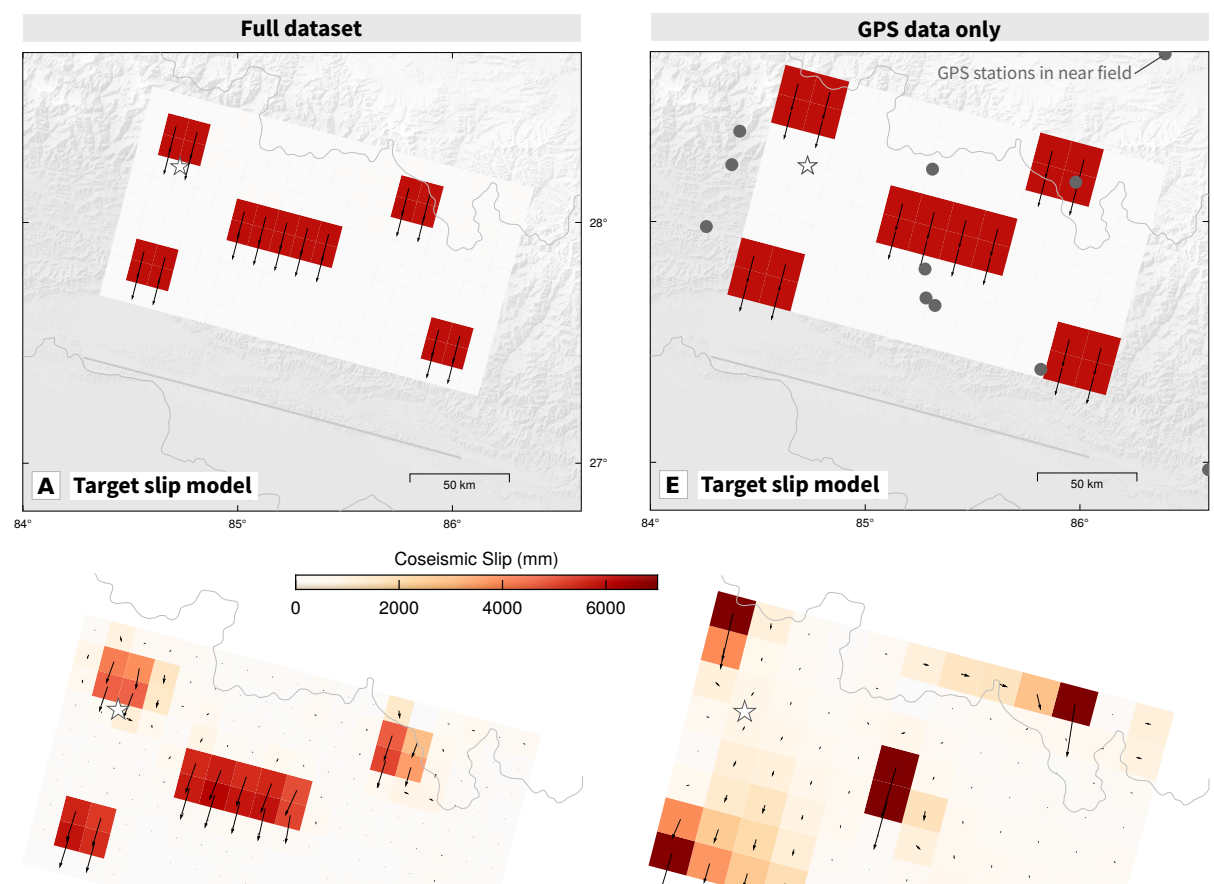

B Non-topographic
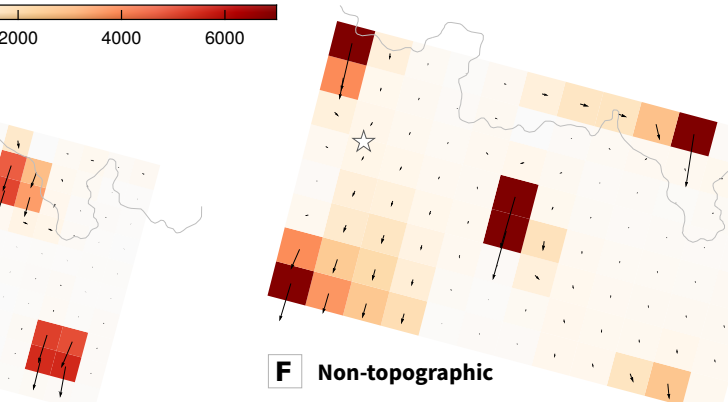

F Non-topographi
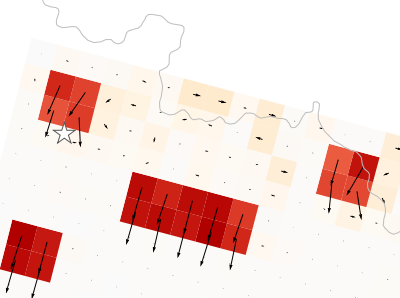

C REC
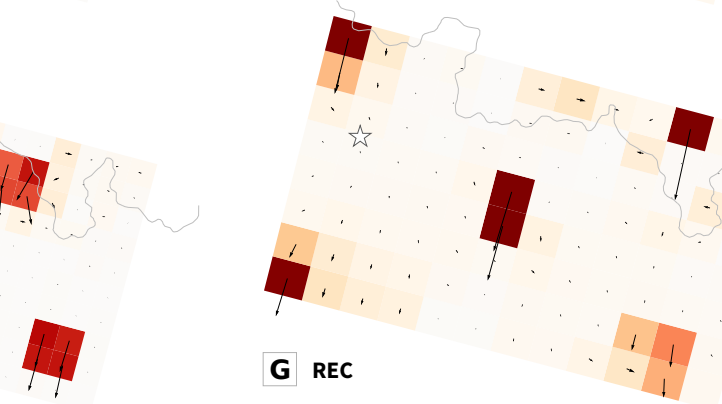

G REC
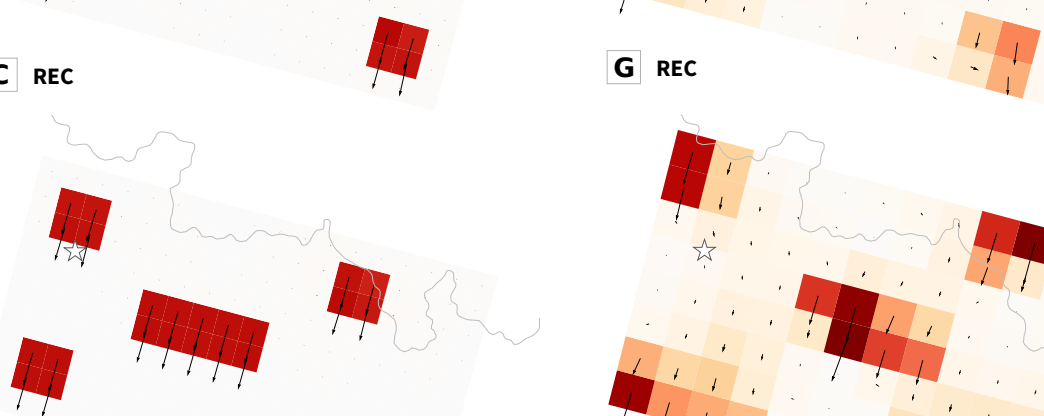

D Topographic
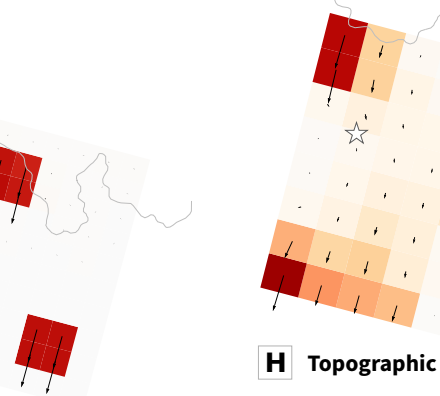

H Topographic

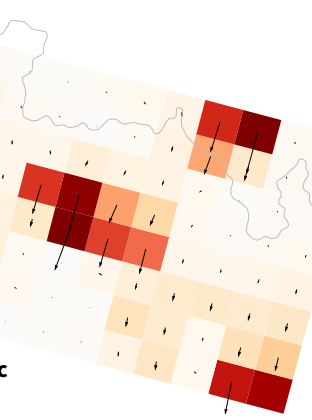

Figure 3: Comparison of slip models estimated from synthetic data for the Gorkha earthquake. (A) and (E): Target slip models used to calculate the full synthetic data set or synthetic GPS-only dataset, respectively. In (E), gray dots show the locations of the GPS stations. The remaining panels show average slip amplitude and rake inferred with non-topographic, REC and topographic Green's functions using the full synthetic data set (left columns) and synthetic GPS data only (right columns). Color scale is the same for all figures. 
elevation correction were able to recover a better slip model than non-topographic Green's functions when the full dataset was used, but they performed more poorly in the GPS-only case. With this in mind, we will now analyze inferred slip distributions found with these different types of topographic results. Our results might therefore imply that non-topographic models are inherently wrong, because they are unable to capture the parameter values imaged with topography.

Figure 5 shows the fit to the observed data using predictions from the topographic model. These fits are quite good, but the observations are fitted well with any of our models. Additional Figures S6, S7 and S8 show the fits to the InSAR data for the non-topographic, topographic and REC models, respectively. Accounting for topography does not significantly improve the fit to the observed data. 



Figure 4: Comparison of finite-fault slip models of the 2015 Gorkha earthquake inferred with the complete dataset of GPS and InSAR data. Slip amplitudes are shown in red, and posterior standard deviations are shown in green. White star shows the location of the epicenter.(A) Map view of average slip amplitude and rake inferred with non-topographic Green's functions. (B) Average slip model inferred with topographic Green's functions. (C) Average slip model inferred with REC Green's functions. (D) Comparison between posterior Probability Density Functions (PDFs) of dip-slip parameters for selected subfaults. PDF colors correspond to amplitude of the average model. Offsets between average models are shown as a percentage of slip amplitude. Plots of posterior PDFs are truncated between 0 and $7 \mathrm{~m}$ to simplify the visualization. 

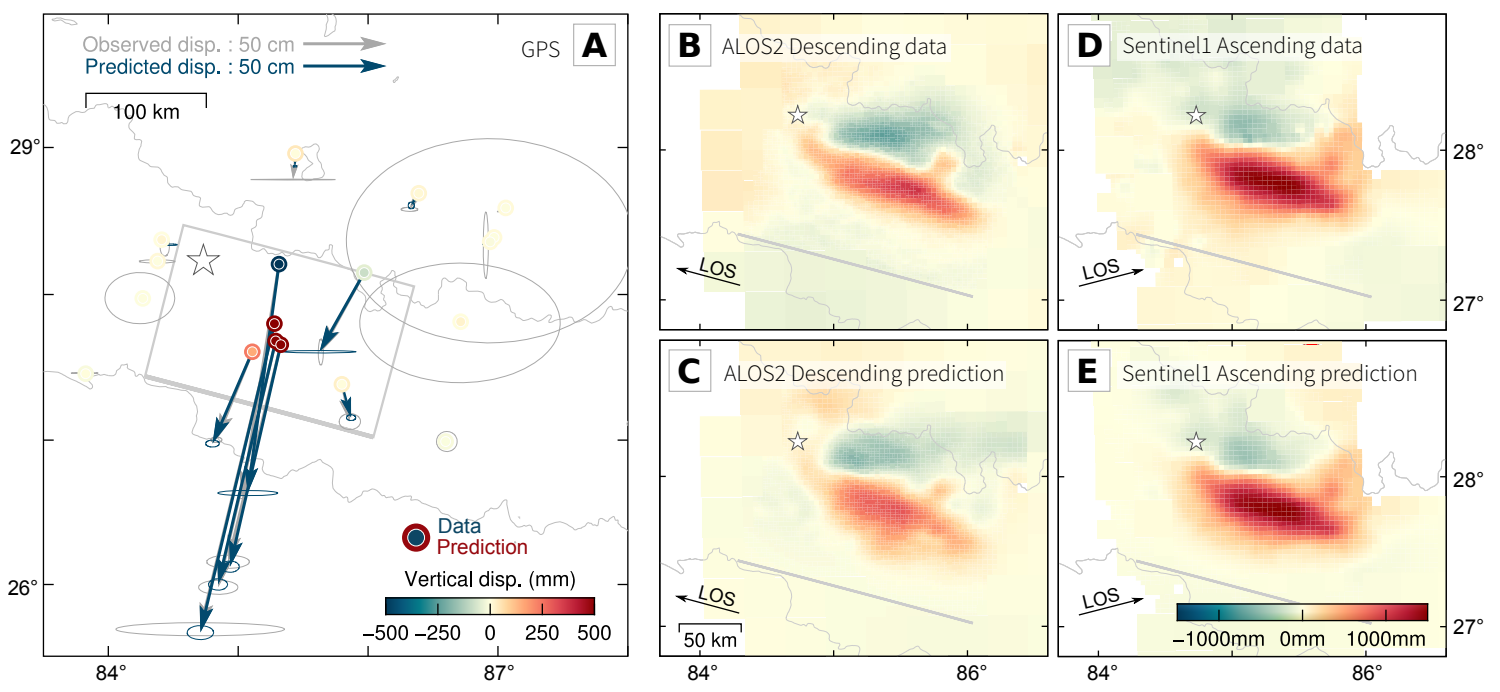

Figure 5: Fit to the observations for the topographic model of the 2015 Gorkha earthquake. (A) Observed and predicted static GPS offsets shown in map view. Observed horizontal surface displacements are in gray with $95 \%$ confidence ellipses, and predicted displacements are in blue with $95 \%$ confidence ellipses. Vertical displacements are color-coded with color-scale truncated at $(-50 \mathrm{~cm}, 50 \mathrm{~cm})$. The inner circle represents the data and the outer circle represents predicted displacements. (B) and (C), respectively: Observed and predicted surface displacement in the line of sight of the ALOS 2 descending interferogram. (D) and (E), respectively: Observed and predicted surface displacement in the line of sight of the Sentinel 1 ascending interferogram. The fault trace is represented with a gray line, and the epicenter with a white star. 


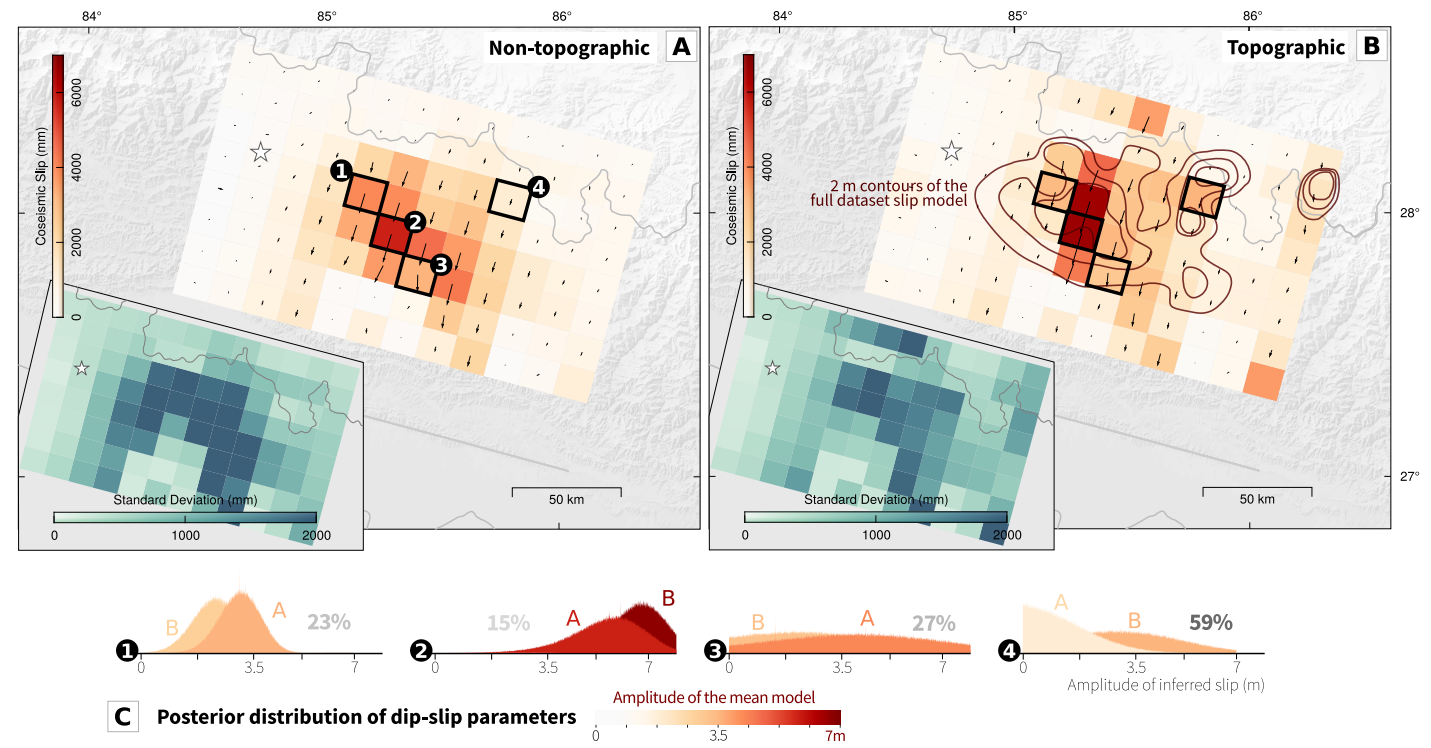

Figure 6: Comparison of finite-fault slip models of the 2015 Gorkha event estimated using the GPS-only dataset. Slip amplitudes are shown in red, and posterior standard deviations are shown in green. White star shows the location of the epicenter.(A) Average slip model inferred with non-topographic Green's functions. (B) Average slip model inferred with topographic Green's functions. (C) Comparison between posterior Probability Density Functions (PDFs) of dip-slip parameters for selected subfaults. PDF colors correspond to amplitude of the average model. Offsets between average models are shown as a percentage of slip amplitude. Plots of posterior PDFs are truncated between 0 and $7 \mathrm{~m}$ to simplify the visualization.

\subsubsection{Slip estimates with GPS data only}

Figure 6 shows that when only GPS data are used, inversions using Green's functions with and without topography yield noticeably different slip distributions. The differences are especially pronounced in the center of the fault, where average slip is $1.5 \mathrm{~m}$ greater for the topographic model, and in the deepest part of the fault on top of which are the largest topographic variations. Given the results of our synthetic tests, we expect that the two high amplitude patches seen in the topographic model (Figure 6(B)) are probably of lesser amplitude. The selected posterior PDFs shown in Figure 6(C) are very broad, and the PDFs from the two inversions overlap significantly. As expected, the slip is thus less constrained than with the full dataset, so the posterior uncertainty is much greater, even with a coarser discretization of the fault plane. However, if the topography is accounted for, the location of large slip is similar whether the full dataset or GPS data only are used (Figure 6(B)). 


\subsubsection{Conclusion for the Gorkha earthquake}

Our analysis of slip models of the Gorkha event suggests that the impact of topography is strongly dependent on slip resolution. When the slip is very well constrained by geodetic data, accounting for topography causes only a slight variation in the principal slip characteristics. We did observe significant changes in the secondary slip information, but these changes were mostly recovered by the receiver elevation correction. On another hand, when the slip is less well constrained (GPS only), neglecting topography had a large impact on the inferred slip distribution. This implies that topography Green's functions will better resolve the slip distribution of events with a limited set of observations. For these events, our results also indicate that the REC approximation is not sufficient.

The Gorkha earthquake is an unusual type of dip-slip event with a very shallow dip angle, good data coverage and directly above the fault plane. This condition generally does not apply to subduction events, where the greatest amount of slip often occurs several tenths of kilometers away from the coast, with all observations on land, and at very different elevations (up to $6 \mathrm{k} \mathrm{m}$ in some cases). In the following section, we investigate the $2010 M_{w} 8.8$ Maule, Chile, earthquake to determine whether these results hold for a subduction setting.

\section{A subduction megathrust test case: the $M_{w} 8.82010$ Maule, Chile, earthquake}

The second earthquake that we investigate is the $M_{w} 8.82010$ Maule, Chile earthquake. This event occurred at the interface between the Nazca and South-American plates, within a region previously recognized as a seismic gap (e.g., Comte et al., 1986; Nishenko, 1991; Ruegg et al., 2009; Madariaga et al., 2010). The slip distribution of this event was studied using geodetic, seismic and/or tsunami data (e.g., Delouis et al., 2010; Vigny et al., 2011; Lay, 2011; Lin et al., 2013; Yue et al., 2014; Yoshimoto et al., 2016).

Our choice of the Maule event was guided by the fact that it is a major and well studied event. It is also located on a subduction zone with a intermediate width (distance from the coast to the trench) of about $100 \mathrm{~km}$. In the most favorable cases, like the Costa Rica and Sumatra subductions, this distance can be reduced to 20 to $30 \mathrm{~km}$, while in cases like Tohoku/North Japan, it is closer to $200 \mathrm{~km}$.

The Maule region, and subductions zones in general, differ from the Gorkha case in three critical ways. First, there are no near-field observations to constrain the shallow slip because usually happening far from coast. As imaging slip on the fault requires to sample the gradient of the surface deformation, in cases like Maule, the distance between parts of the fault and some 
observations can be greater than $200 \mathrm{~km}$. The second major difference is that all data are on one side of the fault (landward) and some distance away from it, thus only covering a fraction of the surface deformation field. Any epistemic error will thus appear as a systematic bias in the Green's functions and is more likely to distort the model space. The third major difference is that observations are spread over two major topography domains, the coastal plain and the Andes mountain range (Figure 1). For both Gorkha and Maule, there are major short wavelength topography variations $\left(40^{\circ}\right.$ slopes over distances of a few $\left.\mathrm{km}\right)$, but a good data coverage across these variations might limit their influence, even if not acknowledged in the Green's functions.

The 2010 Maule earthquake has been intensively studied, and its rupture has been consistently modeled as bilateral, extending over $500 \mathrm{~km}$ along strike. Most of the inferred rupture models show two main slip patches located around longitudes of $35^{\circ} \mathrm{N}$ and $37^{\circ} \mathrm{N}$, with the northern-most patch having higher slip amplitudes. Since the available geodetic data are located onshore, on one side of the rupture and far from the trench, derived rupture characteristics are poorly resolved near the trench. This lack of resolution may explain why most geodetic studies find that the rupture did not reach the shallowest parts of the fault (e.g., Tong et al., 2010; Pollitz et al., 2011; Vigny et al., 2011; Lin et al., 2013) when direct (Maksymowicz et al., 2017) and indirect (Sladen and Trevisan, 2018) observations indicate the opposite. One exception to these geodetic models is the one of Moreno et al. (2012), which imaged a northern slip patch reaching the trench with $5 \mathrm{~m}$ amplitude. Conversely, most studies using seismic data do image moderate slip amplitudes (6-10 m) at the trench (e.g., Delouis et al., 2010; Lay et al., 2010; Koper et al., 2012; Ruiz et al., 2012). This is also supported by deep ocean tsunami data, which are located offshore and on the other side of the rupture, and can provide a better resolution at the trench (Yue et al., 2014; Yoshimoto et al., 2016). Earlier coseismic slip models relying on these tsunami data were probably biased by the fact that they did not consider long wavelength dispersion (e.g., Tsai et al., 2013; Watada et al., 2014; Yue et al., 2014).

Most of the published slip models for the Maule event do not account for the effects of topography and bathymetry. Moreno et al. (2012) did, using a spherical finite element model, and they imaged slip near the trench using geodetic data only. Would this mean that assuming Green's functions with topography can increase the resolution of slip models near the trench? In the following section, we will investigate the effects of topography and bathymetry on inferred slip distributions of the 2010 Maule earthquake. 


\subsection{Data and Forward Model}

4.1.1. Data

Although there are GPS and InSAR data available for the Maule earthquake, we choose to rely on GPS data only for the sake of simplicity and because of the great coverage already provided. The results of Moreno et al. (2012) suggest that although adding InSAR data to the inversion procedure improves the calculated model resolution at the trench by $15-20 \%$, it does not lead to a change in the inferred slip model. Our data consists of 53 static daily offsets processed by Vigny et al. (2011), and continuous GPS and survey sites processed by Lin et al. (2013).

\subsubsection{Crustal domain parameters}

Our model domain extends from $-75.0^{\circ} \mathrm{E}$ to $-68.5^{\circ} \mathrm{E}$ and $-40.3^{\circ} \mathrm{N}$ to $-31.5^{\circ} \mathrm{N}$. The mesh measures approximately $553 \times 958 \times 136 \mathrm{~km}$ and has a mesh spacing of $6 \mathrm{~km}$, for a total of 318400 elements.

${ }_{425}$ This mesh runs on 40 processors in approximately 7.5 minutes. An image of the mesh is shown in Figure S9. The model domain has a Poisson's ratio of 0.25 and Young's modulus of 100.0 GPa. These are the material properties used for the homogeneous model of Chile in Langer et al. (2019). This mesh was only used to generate the Green's functions with topography. For the Green's functions without topography, we used the homogeneous half-space solution at $0 \mathrm{~km}$ elevation.

\subsubsection{Geometry of the assumed fault}

The portion of the slab that ruptured during the Maule earthquake can be approximated as a planar surface, with the exception of a change in strike at around $34^{\circ} \mathrm{S}$ (Hayes et al., 2018 ). We chose to assume a planar fault geometry. Given that our models have almost no inferred slip in the northernmost part of the fault (see Figure S12 of the Supplementary Material), this approximation might not affect our slip estimates. Our fault is $570 \mathrm{~km}$ long and $240 \mathrm{~km}$ wide, with a strike of $198^{\circ}$ a dip of $18^{\circ}$. Since the slip is very poorly constrained near the trench, we experimented with two different fault parameterizations. The first one has homogeneous subfaults measuring $43.8 \mathrm{~km}$ along strike and $24 \mathrm{~km}$ along dip, and in the other parameterization, the two shallowest subfault rows have been merged into 8 bigger subfaults measuring $81.4 \times 48 \mathrm{~km}$. For all subfaults, we use 16900 moment-density tensor patches per subfault when calculating topographic Green's functions with SPECFEM-X. The first parameterization has extremely poor resolution, so in the main text, we only present the results inferred with the second parameterization. The fault geometry parameters are detailed in Table 5 of the Supplementary Material. 


\subsubsection{Other assumed prior information} around the prior value for the fault dip and $(-2 \mathrm{~km}, 2 \mathrm{~km})$ for the fault position.

\subsection{Results}

We will first present the results of synthetic tests, which enable us to analyze the impact of topography on slip estimates without contamination from assumptions made when calculating Green's functions and from data errors. Then we will examine the results of our slip estimates for the Maule earthquake to determine whether Green's functions with topography can impact slip distribution and resolution, particularly near the trench.

\subsubsection{Synthetic Tests}

Our target model for the synthetic tests, shown in Figure 7A, consists of five $\sim 80 \times 48 \mathrm{~km}$ pure dip-slip patches of $20 \mathrm{~m}$ amplitude. These slip patches are located near the trench and at intermediate depth. Using the fault geometry specified in Section 4.1.3, we compute surface displacements due to our target model at the data locations in a topographic domain. We then solve for the slip distribution using these synthetic data and the same fault geometry and crustal structure that were used to generate the data. The resulting slip models found using Green's functions without topography, with the receiver elevation correction, and with topography are shown in Figures 7B,C, and D, respectively. We choose not to add noise to the observations so that the inversion process is only perturbed by changes in the Green's functions. The assumed data error is the same as for the real dataset. We do not account for error due to uncertainty in the fault geometry, since it is perfectly known.

470

Inversions with non-topographic and REC Green's functions fail to capture the target slip model $(7 \mathrm{~B}, \mathrm{C})$. Only two intermediate depth slip patches are even slightly recovered, likely because those patches are located closer to the shore and are therefore better resolved. The resolution is very poor near the trench: estimated slip amplitude is less than $3 \mathrm{~m}$, and the standard deviations are low. Interestingly, the REC model is almost identical to the non-topographic model. This may

be due to the poor slip resolution, since a similar result was found with the GPS-only synthetic 

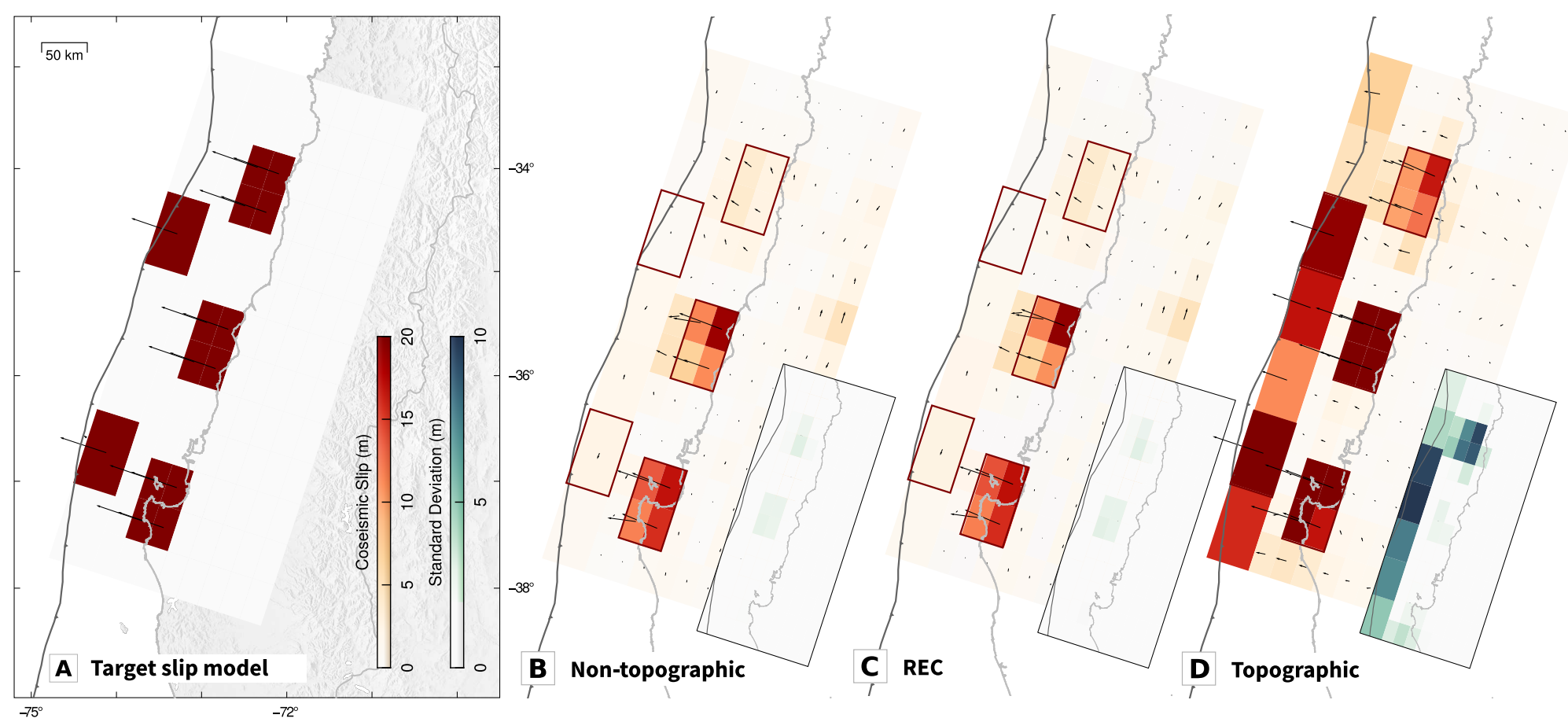

Figure 7: Comparison of slip models estimated from synthetic data for the Maule earthquake. (A) Target slip model used to calculate the synthetic data. (B), (C) and (D), average slip amplitude (red color scale) and rake estimated with non-topographic, REC and topographic Green's functions, respectively. Posterior standard deviations are shown in green at the bottom right of each slip model. 
test of the Gorkha event (Figure 3H). An additional factor may be the steepness of the trench; Williams and Wadge (2000) showed that the REC does not work when topographic gradients are large. This result is also consistent with the findings of Langer et al. (2019) that lowering the surface of a flat mesh to the elevation of the seafloor does not allow one to capture the forward modelling result found with a topographic mesh for the Maule earthquake.

In contrast, the use of topographic Green's functions improves the recovery of the target model (Figure 7D). The two intermediate depth patches that were somewhat recovered by the nontopographic and REC models are well-estimated in the topographic model, and the northernmost intermediate depth slip patch is retrieved too, although with a larger posterior uncertainty. Near the trench, we infer large slip amplitudes with large standard deviations reaching up to $75 \%$ of the slip amplitude. The two patches with the highest slip amplitudes and relatively low posterior uncertainties match the target slip patches. However, we also infer large amplitudes for neighboring subfaults, possibly because the information carried by the topographic Green's functions is too weak to differenciate the target patches from the neighboring subfaults. At least this implies the information brought by the topography allows us to dinstinguish that some slip was shallow. When doing a synthetic test with only the two near-trench slip patches (Figure S10 of the Supplementary Material), we find that the southernmost shallow slip patch is recovered well, although it may be overestimated, and neighboring patches have large slip amplitudes too. The northernmost slip patch is somewhat recovered, but it is underestimated.

The synthetic data are explained well by the predictions of all of our models, whether topography is accounted for or not (Figure S11 of the Supplementary Material). However, only the topographic slip model can recover the synthetic secondary zone of uplift, corresponding to $\sim 20 \mathrm{~cm}$ of upward surface displacement located east of $72^{\circ} \mathrm{W}$ (Figure S11B).

The results of these synthetic tests are similar to our findings for the Gorkha event when using GPS data only: Green's functions without topography are unable to recover slip on some parts of the fault (here, the northern part and at the trench), even when the receiver elevation correction is used. When Green's functions with topography are used, resolution of the slip patches is much better.

\subsubsection{Slip Estimates}

505

Using the real data from the 2010 Maule event, we now invert for slip models using nontopographic, REC and topographic Green's functions. The inferred slip models, shown in Figure 8, are all characterized by two main high-amplitude slip patches located at intermediate depth, around $35^{\circ} \mathrm{S}$ and $37^{\circ} \mathrm{S}$. This slip distribution is similar to the ones found by previous studies discussed 

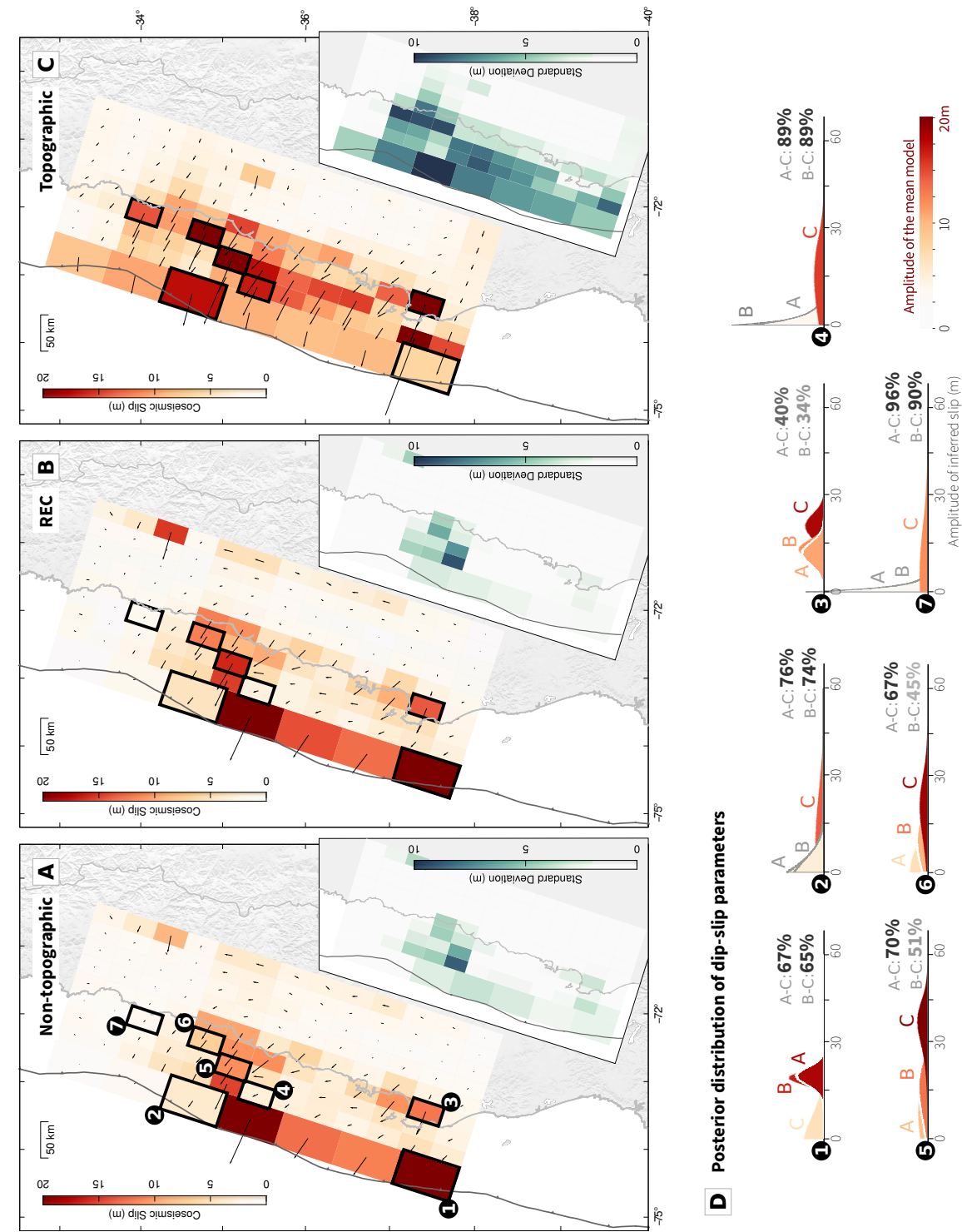

Figure 8: Comparison of finite-fault slip models of the 2010 Maule earthquake. Slip amplitudes are shown in red and posterior standard deviations for each slip model are shown in green. (A) Average slip amplitude and rake inferred with non-topographic Green's functions. (B) Average slip model inferred with REC Green's functions. (C) Average slip model inferred with topographic Green's functions. (D) Comparison between posterior Probability Density Functions (PDFs) of dip-slip parameters for selected subfaults. PDF colors correspond to amplitude of the average model. Offsets between average models are shown as a percentage of slip amplitude. Plots of the posterior PDFs are truncated between 0 and $60 \mathrm{~m}$ to simplify the visualization. 
in Section 4. The non-topographic and REC models (Figures 8A,B) are nearly identical, with

large slip amplitudes of up to $20 \mathrm{~m}$ near the trench in the southern half of the fault, and some slip estimated on the deepest row. The slip appears well constrained in the southern half of the fault, with reasonably small standard deviations (Figure 8D, subfaults (1) and (3)). Posterior uncertainty is higher for the northern half of the fault, with larger or Dirichlet-shaped posterior PDFs (Figure 8D, subfaults (2), (5) and (6)).

The topographic slip model (Figure $8 \mathrm{C}$ ) is very different from the two other results. The two intermediate-depth high slip patches still have large amplitudes (up to $20 \mathrm{~m}$ ), but there are also intermediate-depth subfaults with moderate slip amplitudes in between those two patches. The most striking difference is that only the northern slip patch reaches the trench, with up to $17 \mathrm{~m}$ of slip, and very small slip amplitudes are inferred near the trench in the southern half of the fault. Overall, posterior uncertainties (Figure 8D) are larger, and can often be greater than 50\% of the slip amplitude. Given the results of the synthetic tests presented in the previous section, the topographic slip model is the only one able to provide meaningful results, even if associated with greater uncertainties. We note that this model is also coherent with the tsunami data (e.g., Yue et al., 2014; Yoshimoto et al., 2016), outer-rise aftershock distribution (Sladen and Trevisan, 2018) and a differential bathymetry study (Maksymowicz et al., 2017). Again, from the synthetic tests, we can suggest the medium slip amplitudes $(5-10 \mathrm{~m})$ along the trench are probably artefacts (also because the mean of the Dirichlet shape of the PDFs does not reflect the posterior mean), but the high amplitude patch $(\sim 17 \mathrm{~m})$ imaged above the northern patch are likely realistic.

The slip model with the receiver elevation correction shows behavior that is consistent with the results of our synthetic tests. Average slip values for the REC model are approximately halfway in between average non-topographic and topographic slip values for intermediate depth subfaults (Figure 8D, subfaults (3) to (6)), but is very close to the non-topographic slip values for the neartrench subfaults (Figure 8D, subfaults (1) and (2)). This suggests that the REC only improves our estimates where slip resolution is large enough, and is not effective at the trench where resolution is too low.

As discussed in Section 4.1.3, we performed similar slip inversions using a fault parameterized with homogeneous subfaults. This fault parametrization also yields very different results with topographic and non-topographic Green's functions, particularly near the trench where average slip reaches $20 \mathrm{~m}$ of amplitude for the non-topographic and REC models, but is close to $0 \mathrm{~m}$ in the topographic model (Figure S12 of the Supplementary Material). However, the near-trench posterior PDFs for the non-topographic and REC models are close to the uniform distribution (Figure S12D, subfaults (2) and (3) in particular), implying that the resolution at the trench is 
so poor that the results are not meaningful. However, the resolution is better in the topographic model.

The fit of our model predictions to the data are shown in Figures 9 (for topographic and non-topographic Green's functions) and S13 (for REC Green's functions). Vertical and horizontal displacements appear to be well explained by both non-topographic and topographic models. There are two West-East rows of stations that can be used to investigate the fit in more detail. The predicted horizontal displacements are similar for both the topographic and non-topographic models, and both provide a good fit to the observations within the data errors and the posterior uncertainties of the predictions (Figure 9). However, the non-topographic model has difficulty explaining the complex shape and amplitude of uplift near the shoreline for both profiles: data points fall outside the prediction zone, which is shown as a gray area around the profiles. In contrast, the topographic model provides a better fit to the observed vertical surface displacement, especially near the coast. Note the large difference between the prediction uncertainties for the vertical displacements in the topographic and non-topographic profiles. This is because posterior slip uncertainty is greater in the topographic model, especially at shallow and intermediate depths.

\subsubsection{Conclusion for the Maule earthquake}

Our investigation of the Maule event indicates that the use of topographic Green's functions improves the slip resolution near the trench. Our synthetic tests indicate that the average topographic slip model seems to represent a better estimate of the "real" slip, even if the associated posterior uncertainties are larger. Only the topographic Green's function allow to explain some features of the vertical displacement data. Our results also demonstrate that the Receiver Elevation Correction is not a sufficient proxy for topographic Green's functions, especially for areas where slip is poorly constrained, such as near the trench.

\section{Discussion and Conclusions}

Topographic variations are rarely accounted for in finite fault slip inversions, even when earthquakes take place in regions where they are the largest. Previous research (e.g., Hsu et al., 2011; Langer et al., 2019) showed that topography can have a significant effect on estimated surface displacements. In this study, we extended that work by assessing the effect of topography on static earthquake slip inversions. Indeed, even if small, a difference in the shape of the Green's functions might have strong influence on slip estimates.

With SPECFEM-X, a quasi-static integrated spectral element software package, we are able to efficiently compute Green's functions in a topographic domain. We used SPECFEM-X to investi- 

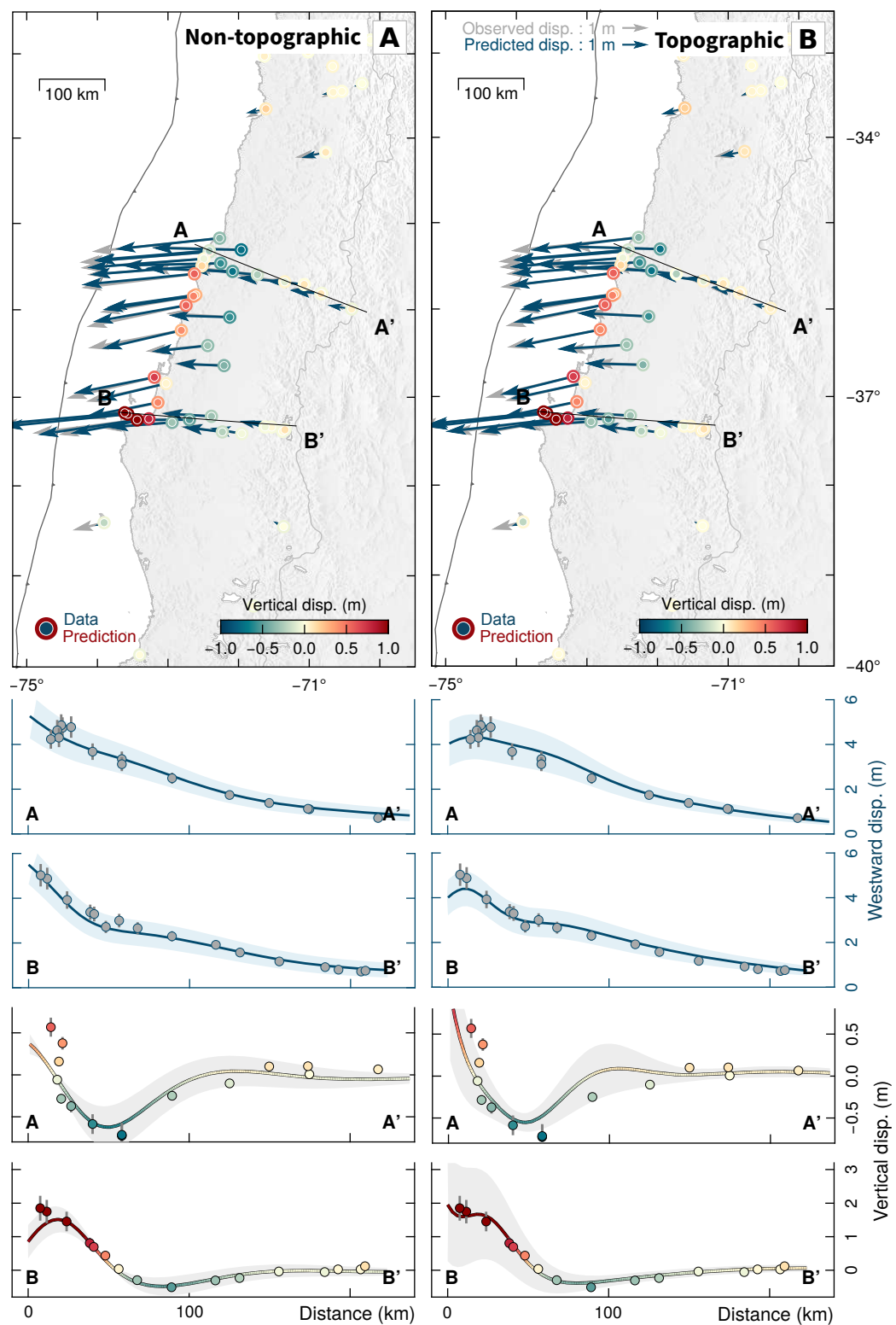

Figure 9: Comparison between static GPS offsets and predicted surface displacements for slip models of the Maule earthquake. Top panels show horizontal and vertical displacements in map view, along with predictions from non-topographic (A) and topographic (B) models. Inner circles show the data and outer circles show predictions. Observed horizontal surface displacements are in gray with $95 \%$ confidence ellipses, and predicted displacements are in blue with $95 \%$ confidence ellipses. Vertical displacements are color-coded with color-scale truncated at $(-1 \mathrm{~m}$, $1 \mathrm{~m})$. Lower panels: Profiles A-A' at $35.5^{\circ} \mathrm{S}$ and B-B' at $37.5^{\circ} \mathrm{S}$. For each profile, horizontal displacements are shown with gray dots and error bars for the data and a blue line with light blue area for predictions and associated posterior uncertainties. Vertical displacements are represented with the same color-scale as in the map view, with dots and error bars for the data and a line with light gray area for predictions and uncertainties. 


$$
\text { In this case, the REC approximation is not sufficient and is probably not enough to guide the model }
$$
exploration in the right direction.

\subsection{Impact of topography and REC on slip models}

For both earthquakes, the use of Green's functions with topography produced different slip distributions. This effect was more pronounced when the slip was poorly resolved (GPS data only). In this case, the topographic and non-topographic results differed greatly, and the receiver elevation correction failed to recover any of the differences in the topographic model. When the slip sensitivity was high, the difference between topographic and non-topographic models was much less and most of these differences could be recovered with the receiver elevation correction.

The receiver elevation correction accounts for variations in distance between the fault and the surface, but neglects the shape of the topographic surface (Williams and Wadge, 2000). It was previously known that the REC fails when topographic gradients are large (Williams and Wadge, 2000), as they are in the Maule region. In this study, we found that data resolution also plays a large role in determining when the REC will be effective. If the slip is well constrained by observations, the secondary complexities of Green's functions will add little information to the inverse problem. In such a case, accounting for topography will lead to only a slight improvement in the inferred models, and the REC approximation might be sufficient. In contrast, if the slip is poorly constrained by the observations (typically the case for large subduction earthquakes), topography will have an impact on the Green's functions and strongly bias the inferred slip models. In this case, the REC approximation is not sufficient and is probably not enough to guide the model 
If observational constraints are not densely and homogeneously distributed around the rupture, we can only improve inferred models by accounting for the full effect of topography. In particular, this will drastically improve slip resolution where topographic gradients are large and the data is uninformative: at depths for the Gorkha event, and near the trench for the Maule event. The effect of the shape of the topographic surface on the Green's functions is particularly large for the near trench parameters of the Maule event (Figure S14 of the Supplementary Material), which explains why the REC fails. We also find that topographic Green's functions are the only ones able to explain complexities of the surface uplift.

We therefore conclude that the effect of topography on static slip models will be significant, and can only sometimes be accounted for using the receiver elevation correction. Our findings suggest that, in many cases, it is advisable to use topographic Green's functions when inferring slip models in regions with strong topographic gradients and/or poor observational constraints, such as in a subduction zone. In regions with excellent data coverage (e.g. InSAR data with two different lines-of-sight), the REC may be used to account for topography.

\subsection{Perspectives}

Although the two examples of Gorkha and Maule represent two end members of topography and data coverage, they are not sufficient for a complete understanding of the impact of topography on static slip inversions because they both belong to the same class of earthquake - namely, dip-slip events that occur close to the surface on shallowly dipping faults. Additional research is needed to determine whether the results found in this work extend to other types of earthquakes and faults. Does topography still have a significant effect when deformation is mostly horizontal, as it is for a strike-slip fault? Furthermore, it seems intuitive that deeper earthquakes would sense topography less. Is there a cut-off depth below which topography can be neglected? What role, if any, does the dip of a fault play? How extreme must the topography of a region be for the effect to start being considered significant? Topography may be short-wavelength (many small structures) or long-wavelength (several large features); does the length scale of the topography matter when determining whether it is likely to be impactful?

We must also remember that topography is only one aspect of 3D Earth structure. In this study, we chose to focus on topography because the results of a previous study (Langer et al., 2019) implied that it was likely to have the greatest impact on inferred slip models of the earthquakes that we analyzed in this study. Additionally, topography is an unusual attribute of the forward model because it is known everywhere with sufficient precision and can be assumed a priori. Unlike topography, fault geometry and elastic structure are only estimated for a limited number of 
regions. In regions where these properties are poorly known, a good approach is to estimate their uncertainty (e.g., Minson et al., 2013; Duputel et al., 2014; Ragon et al., 2018, 2019b). However, fault geometry and elastic heterogeneity also play a role in perturbing surface deformation. These effects have been investigated by a few studies (see Section 1 for a thorough review), but since they can take many forms, their generic impact is not yet known. More research is needed before we can start to determine the trade-offs between these different contributions.

Finally, our conclusions apply not only to coseismic deformation; topography may also affect estimates of postseismic stress relaxation, which is generally modeled by several interacting mechanisms, such as afterslip (e.g., Marone et al., 1991) or viscoelastic deformation in the lower crust or mantle (e.g., Pollitz et al., 1998; Perfettini and Avouac, 2004; Barbot and Fialko, 2010). Afterslip is generally of lower amplitude than coseismic deformation, and is thus constrained by less informative observations. The impact of topography on afterslip estimates is therefore probably even greater than for coseismic slip models. In contrast, viscoelastic deformation usually occurs at greater depths (e.g., Pollitz et al., 1998), so its estimates might be less influenced by topography. Additionally, topography may affect images of interseismic slip rate deficit (or kinematic coupling ratio), which is usually modeled to decipher which portions of thrust faults are likely to rupture and which portions slip aseismically. A megathrust is usually coupled at intermediate to shallow depths (e.g. Stevens and Avouac, 2015; Xue et al., 2015; Métois et al., 2016; Michel et al., 2019). Almeida et al. (2018a) concluded that the coupling is generally underestimated in shallow regions, and thus where model resolution is low and topographic gradients are high. Yet, megathrust coupling is usually modeled using the homogeneous elastic half-space approximation (e.g. Chlieh et al., 2011; Loveless and Meade, 2016; Nocquet et al., 2017; Dal Zilio et al., 2019, and previous citations). Incorporating 3D complexity would be more easily done if Green's functions with 3D structure, especially topography, could be calculated automatically by SPECFEM-X with minimal input from the user. The main barrier towards achieving this goal is that mesh generation is a complex process. High-quality topographic meshes are often difficult to construct, even with the simple requirements of SPECFEM-X, and each mesh must be fine-tuned by hand. However, we do plan to share the scripts required to produce the Green's functions used in this study on Github so that others may use them as a guide.

In summary, we showed that neglecting topography can lead to biased estimates of slip distribution on faults, especially in areas where slip is more difficult to resolve. Accounting for topography, something which can now be done almost routinely with numerical tools such as SPECFEM-X, is thus an essential ingredient towards achieving a reliable and detailed estimate of fault slip behavior (slip episodes or slip deficit) in region with large topographic variations. 


\section{Acknowledgements}

We are grateful to Raphael Grandin who shared his processed Sentinel 1 InSAR data (Grandin et al., 2015). This research used computational resources provided by the Princeton Institute for Computational Science \& Engineering (PICSciE). The Bayesian simulations were performed with the AlTar package (https://github.com/AlTarFramework/altar), on the HPC-Regional Center ROMEO (https://romeo.univ-reims.fr) of the University of Reims Champagne-Ardenne (France). The Classic Slip Inversion (CSI) Python library (Jolivet et al., 2014) created by Romain Jolivet was used to build inputs for the Bayesian algorithm, in particular to compute non-topographic Green's functions. 3D data were visualized using the open-source parallel visualization software ParaView/VTK (www.paraview.org). Figures were generated with the Matplotlib and Seaborn (doi:10.5281/zenodo.1313201) Python libraries and with the Generic Mapping Tools library (Wessel et al., 2019). This study was partly supported by the French National Research Agency ANR JCJC E-POST (ANR-14-CE03-002-01JCJC 'E-POST'). Théa Ragon was supported by a fellowship from the French Ministry of Higher Education and is supported by a fellowship from the Caltech GPS Division. 
Almeida, R., Lindsey, E.O., Bradley, K., Hubbard, J., Mallick, R., Hill, E.M., 2018a. Can the Updip Limit of Frictional Locking on Megathrusts Be Detected Geodetically? Quantifying the Effect of Stress Shadows on Near-Trench Coupling. Geophysical Research Letters 45, 4754-4763. doi:10.1029/2018GL077785.

Almeida, R.V., Hubbard, J., Liberty, L., Foster, A., Sapkota, S.N., 2018b. Seismic imaging of the Main Frontal Thrust in Nepal reveals a shallow décollement and blind thrusting. Earth and Planetary Science Letters 494, 216-225. URL: http://www. sciencedirect.com/science/ article/pii/S0012821X18302486.

Aster, R.C., Borchers, B., Thurber, C.H., 2005. Parameter Estimation and Inverse Problems. Academic Press.

Barbot, S., Fialko, Y., 2010. A unified continuum representation of post-seismic relaxation mechanisms: Semi-analytic models of afterslip, poroelastic rebound and viscoelastic flow. Geophysical Journal International 182, 1124-1140. doi:10.1111/j.1365-246X.2010.04678.x.

Beresnev, I.A., 2003. Uncertainties in Finite-Fault Slip Inversions: To What Extent to Believe? (A Critical Review). Bulletin of the Seismological Society of America 93, 2445-2458. doi:10. $1785 / 0120020225$.

Causse, M., Cotton, F., Mai, P.M., 2010. Constraining the roughness degree of slip heterogeneity. J. Geophys. Res. 115. doi:10.1029/2009jb006747.

Chlieh, M., Perfettini, H., Tavera, H., Avouac, J.P., Remy, D., Nocquet, J.M., Rolandone, F., Bondoux, F., Gabalda, G., Bonvalot, S., 2011. Interseismic coupling and seismic potential along the Central Andes subduction zone. Journal of Geophysical Research: Solid Earth 116. doi:10.1029/2010JB008166.

Comte, D., Eisenberg, A., Lorca, E., Pardo, M., Ponce, L., Saragoni, R., Singh, S.K., Suárez, G., 1986. The 1985 Central Chile Earthquake: A Repeat of Previous Great Earthquakes in the Region? Science 233, 449-453. doi:10.1126/science.233.4762.449.

Dahlen, F.A., Tromp, J., 1998. Theoretical Global Seismology. Princeton University Press.

Dal Zilio, L., Jolivet, R., van Dinther, Y., 2019. Segmentation of the Main Himalayan Thrust Inferred from Geodetic Observations of Interseismic Coupling. Preprint. EarthArXiv. doi:10. 31223/osf.io/tkjef. 
Delouis, B., Nocquet, J.M., Vallée, M., 2010. Slip distribution of the February 27, 2010 Mw = 8.8 Maule Earthquake, central Chile, from static and high-rate GPS, InSAR, and broadband teleseismic data. Geophysical Research Letters 37. doi:10.1029/2010GL043899.

Du, Y., Aydin, A., Segall, P., 1992. Comparison of various inversion techniques as applied to the determination of a geophysical deformation model for the 1983 Borah Peak earthquake. bssa 82, $1840-1866$.

Duputel, Z., Agram, P.S., Simons, M., Minson, S.E., Beck, J.L., 2014. Accounting for prediction uncertainty when inferring subsurface fault slip. Geophysical Journal International 197, 464-482. doi:10.1093/gji/ggt517.

Elliott, J., Jolivet, R., González, P.J., Avouac, J.P., Hollingsworth, J., Searle, M.P., Stevens, V., 2016. Himalayan megathrust geometry and relation to topography revealed by the Gorkha earthquake. Nature Geoscience 9, 174-180. URL: https://doi.org/10.1038/ngeo2623.

Feng, G., Zhu, J., Li, Z., Zhang, G., Shan, X., Zhang, L., 2015. Geodetic model of the 2015 April 25 Mw 7.8 Gorkha Nepal Earthquake and Mw 7.3 aftershock estimated from InSAR and GPS data. Geophysical Journal International 203, 896-900. doi:10.1093/gji/ggv335.

Galetzka, J., Melgar, D., Genrich, J.F., Geng, J., Owen, S., Lindsey, E.O., Xu, X., Bock, Y., Avouac, J.P., Adhikari, L.B., Upreti, B.N., Pratt-Sitaula, B., Bhattarai, T.N., Sitaula, B.P., Moore, A., Hudnut, K.W., Szeliga, W., Normandeau, J., Fend, M., Flouzat, M., Bollinger, L., Shrestha, P., Koirala, B., Gautam, U., Bhatterai, M., Gupta, R., Kandel, T., Timsina, C., Sapkota, S.N., Rajaure, S., Maharjan, N., 2015. Slip pulse and resonance of the Kathmandu basin during the 2015 Gorkha earthquake, Nepal. Science 349, 1091-1095. URL: https:// science.sciencemag. org/content/349/6252/1091, doi:10.1126/science.aac6383.

Gallovič, F., Imperatori, W., Mai, P.M., 2015. Effects of three-dimensional crustal structure and smoothing constraint on earthquake slip inversions: Case study of the Mw 6.3 2009 L'Aquila earthquake. Journal of Geophysical Research: Solid Earth 120, 428-449. doi:10.1002/2014JB011650.

Gharti, H.N., Langer, L., Tromp, J., 2019. Spectral-infinite-element simulations of coseismic and post-earthquake deformation. Geophysical Journal International 216, 1364-1393. URL: http://dx.doi.org/10.1093/gji/ggy495, doi:10.1093/gji/ggy495.

Gombert, B., Duputel, Z., Jolivet, R., Doubre, C., Rivera, L., Simons, M., 2017. Revisiting 
the 1992 Landers earthquake: a Bayesian exploration of co-seismic slip and off-fault damage. Geophysical Journal International 212, 839-852. doi:10.1093/gji/ggx455.

Grandin, R., Vallée, M., Satriano, C., Lacassin, R., Klinger, Y., Simoes, M., Bollinger, L., 2015. Rupture process of the $\mathrm{Mw}=7.92015$ Gorkha earthquake (Nepal): Insights into Himalayan megathrust segmentation. Geophysical Research Letters 42, 8373-8382. doi:10.1002/ $2015 g 1066044$.

Hartzell, S., Liu, P., Mendoza, C., Ji, C., Larson, K.M., 2007. Stability and Uncertainty of FiniteFault Slip Inversions: Application to the 2004 Parkfield, California, Earthquake. Bulletin of the Seismological Society of America 97, 1911-1934. doi:10.1785/0120070080.

Hayes, G.P., Moore, G.L., Portner, D.E., Hearne, M., Flamme, H., Furtney, M., Smoczyk, G.M., 2018. Slab2, a comprehensive subduction zone geometry model. Science 362, 58-61. doi:10. 1126/science. aat4723.

Hsu, Y.J., Simons, M., Williams, C., Casarotti, E., 2011. Three-dimensional FEM derived elastic Green's functions for the coseismic deformation of the $2005 \mathrm{Mw} 8.7$ Nias-Simeulue, Sumatra earthquake. Geochemistry, Geophysics, Geosystems 12. URL: https://agupubs . onlinelibrary.wiley.com/doi/abs/10.1029/2011GC003553, doi:10.1029/2011GC003553, arXiv:https://agupubs .onlinelibrary.wiley.com/doi/pdf/10.1029/2011GC003553.

Huang, B.S., Yeh, Y.T., 1997. Effect of Near-fault Terrain upon Dislocation Modeling. pure and applied geophysics 150, 1-18. doi:10.1007/s000240050060.

Jolivet, R., Duputel, Z., Riel, B., Simons, M., Rivera, L., Minson, S.E., Zhang, H., Aivazis, M.a.G., Ayoub, F., Leprince, S., Samsonov, S., Motagh, M., Fielding, E.J., 2014. The 2013 Mw 7.7 Balochistan Earthquake: Seismic Potential of an Accretionary Wedge. Bulletin of the Seismological Society of America 104, 1020-1030. doi:10.1785/0120130313.

Jolivet, R., Lasserre, C., Doin, M.P., Guillaso, S., Peltzer, G., Dailu, R., Sun, J., Shen, Z.K., Xu, X., 2012. Shallow creep on the Haiyuan fault (Gansu, China) revealed by SAR interferometry. Journal of Geophysical Research: Solid Earth 117. URL: https://agupubs.onlinelibrary . wiley.com/doi/abs/10.1029/2011JB008732, doi:10.1029/2011JB008732.

Koper, K.D., Hutko, A.R., Lay, T., Sufri, O., 2012. Imaging short-period seismic radiation from the 27 February 2010 Chile (MW 8.8) earthquake by back-projection of P, PP, and PKIKP waves. Journal of Geophysical Research: Solid Earth 117. doi:10.1029/2011JB008576. 
Kyriakopoulos, C., Masterlark, T., Stramondo, S., Chini, M., Bignami, C., 2013. Coseismic slip distribution for the Mw 92011 Tohoku-Oki earthquake derived from 3-D FE modeling. Journal of Geophysical Research: Solid Earth 118, 3837-3847. URL: https://agupubs . onlinelibrary.wiley.com/doi/abs/10.1002/jgrb.50265, doi:10.1002/jgrb.50265, arXiv:https://agupubs. onlinelibrary.wiley.com/doi/pdf/10.1002/jgrb. 50265.

Langer, L., Gharti, H.N., Tromp, J., 2019. Impact of topography and three-dimensional heterogeneity on coseismic deformation. Geophysical Journal International 217, 866-878. doi:10.1093/gji/ggz060.

Lay, T., 2011. A Chilean surprise. Nature 471, 174-175. doi:10.1038/471174a.

Lay, T., Ammon, C.J., Kanamori, H., Koper, K.D., Sufri, O., Hutko, A.R., 2010. Teleseismic inversion for rupture process of the 27 February 2010 Chile (Mw 8.8) earthquake. Geophysical Research Letters 37. doi:10.1029/2010GL043379.

Lin, Y.n.N., Sladen, A., Ortega-Culaciati, F., Simons, M., Avouac, J.P., Fielding, E.J., Brooks, B.A., Bevis, M., Genrich, J., Rietbrock, A., Vigny, C., Smalley, R., Socquet, A., 2013. Coseismic and postseismic slip associated with the 2010 Maule Earthquake, Chile: Characterizing the Arauco Peninsula barrier effect. Journal of Geophysical Research: Solid Earth 118, 3142-3159. doi:10.1002/jgrb.50207.

Lindsey, E.O., Natsuaki, R., Xu, X., Shimada, M., Hashimoto, M., Melgar, D., Sandwell, D.T., 2015. Line-of-sight displacement from ALOS-2 interferometry: Mw 7.8 Gorkha earthquake and Mw 7.3 aftershock. Geophysical Research Letters 42, 6655-6661. doi:10.1002/2015gl065385.

Liu, W., Yao, H., 2018. A New Strategy of Finite-Fault Inversion Using Multiscale Waveforms and Its Application to the 2015 Gorkha, Nepal, Earthquake. Bulletin of the Seismological Society of America 108, 1947-1961. URL: https://doi.org/10.1785/0120170309, doi:10. $1785 / 0120170309$.

Lohman, R.B., Simons, M., 2005. Some thoughts on the use of InSAR data to constrain models of surface deformation: Noise structure and data downsampling. Geochemistry, Geophysics, Geosystems 6. URL: https://agupubs.onlinelibrary.wiley.com/doi/abs/10. 1029/2004GC000841, doi:10.1029/2004GC000841.

Loveless, J.P., Meade, B.J., 2016. Two decades of spatiotemporal variations in subduction zone coupling offshore Japan. Earth and Planetary Science Letters 436, 19-30. doi:10.1016/j . epsl. 2015.12.033. 
Madariaga, R., Métois, M., Vigny, C., Campos, J., 2010. Central Chile Finally Breaks. Science 328, 181-182. doi:10.1126/science.1189197.

Maksymowicz, A., Chadwell, C., Ruiz, J., Tréhu, A., Contreras-Reyes, E., Weinrebe, W., DíazNaveas, J., Gibson, J., Lonsdale, P., Tryon, M., 2017. Coseismic seafloor deformation in the trench region during the mw8. 8 maule megathrust earthquake. Scientific reports 7, 1-8.

Mansinha, L.a., Smylie, D., 1971. The displacement fields of inclined faults. Bulletin of the Seismological Society of America 61, 1433-1440.

Marone, C.J., Scholtz, C.H., Bilham, R., 1991. On the mechanics of earthquake afterslip. Journal of Geophysical Research: Solid Earth 96, 8441-8452. doi:10.1029/91JB00275.

Masterlark, T., 2003. Finite element model predictions of static deformation from dislocation sources in a subduction zone: Sensitivities to homogeneous, isotropic, Poisson-solid, and half-space assumptions. Journal of Geophysical Research: Solid Earth 108. doi:10.1029/ 2002 JB002296.

McTigue, D.F., Segall, P., 1988. Displacements and tilts from dip-slip faults and magma chambers beneath irregular surface topography. Geophysical Research Letters 15, 601-604. doi:10.1029/ GL015i006p00601.

Mendoza, M.M., Ghosh, A., Karplus, M.S., Klemperer, S.L., Sapkota, S.N., Adhikari, L.B., Velasco, A., 2019. Duplex in the Main Himalayan Thrust illuminated by aftershocks of the 2015 Mw 7.8 Gorkha earthquake. Nature Geoscience URL: https://doi.org/10.1038/ s41561-019-0474-8.

Métois, M., Vigny, C., Socquet, A., 2016. Interseismic Coupling, Megathrust Earthquakes and Seismic Swarms Along the Chilean Subduction Zone (38-18S). Pure and Applied Geophysics 173, 1431-1449. doi:10.1007/s00024-016-1280-5.

Michel, S., Gualandi, A., Avouac, J.P., 2019. Interseismic Coupling and Slow Slip Events on the Cascadia Megathrust. Pure and Applied Geophysics 176, 3867-3891. doi:10.1007/ s00024-018-1991-x.

Minson, S.E., Simons, M., Beck, J.L., 2013. Bayesian inversion for finite fault earthquake source models I-theory and algorithm. Geophysical Journal International 194, 1701-1726. doi:10. $1093 / g j i / g g t 180$. 
Moreno, M., Melnick, D., Rosenau, M., Baez, J., Klotz, J., Oncken, O., Tassara, A., Chen, J., Bataille, K., Bevis, M., Socquet, A., Bolte, J., Vigny, C., Brooks, B., Ryder, I., Grund, V., Smalley, B., Carrizo, D., Bartsch, M., Hase, H., 2012. Toward understanding tectonic control on the Mw 8.82010 Maule Chile earthquake. Earth and Planetary Science Letters 321-322, 152-165. doi:10.1016/j.epsl.2012.01.006.

Nishenko, S.P., 1991. Circum-Pacific Seismic Potential: 1989-1999, in: Okal, E.A. (Ed.), Aspects of Pacific Seismicity. Birkhäuser, Basel. Pageoph Topical Volumes, pp. 169-259. doi:10.1007/ 978-3-0348-5639-3_2.

Nocquet, J.M., Jarrin, P., Vallée, M., Mothes, P.A., Grandin, R., Rolandone, F., Delouis, B., Yepes, H., Font, Y., Fuentes, D., Régnier, M., Laurendeau, A., Cisneros, D., Hernandez, S., Sladen, A., Singaucho, J.C., Mora, H., Gomez, J., Montes, L., Charvis, P., 2017. Supercycle at the Ecuadorian subduction zone revealed after the 2016 Pedernales earthquake. Nature Geoscience 10, 145-149. doi:10.1038/ngeo2864.

Nábělek, J., Hetényi, G., Vergne, J., Sapkota, S., Kafle, B., Jiang, M., Su, H., Chen, J., Huang, B.S., Team, t.H.C.L.I.M.B., 2009. Underplating in the Himalaya-Tibet collision zone revealed by the Hi-CLIMB experiment. Science 325, 1371-1374. URL: http://science.sciencemag. org/content/325/5946/1371. abstract.

Okada, Y., 1992. Internal deformation due to shear and tensile faults in a half-space. Bulletin of the Seismological Society of America 82, 1018-1040.

Perfettini, H., Avouac, J.P., 2004. Postseismic relaxation driven by brittle creep: A possible mechanism to reconcile geodetic measurements and the decay rate of aftershocks, application to the Chi-Chi earthquake, Taiwan. Journal of Geophysical Research: Solid Earth 109, B02304. doi:10.1029/2003JB002488.

Pollitz, F., Brooks Ben, Tong Xiaopeng, Bevis Michael G., Foster James H., Bürgmann Roland, Smalley Robert, Vigny Christophe, Socquet Anne, Ruegg Jean-Claude, Campos Jaime, Barrientos Sergio, Parra Héctor, Soto Juan Carlos Baez, Cimbaro Sergio, Blanco Mauro, 2011. Coseismic slip distribution of the February 27, $2010 \mathrm{Mw} 8.8$ Maule, Chile earthquake. Geophysical Research Letters 38. doi:10.1029/2011GL047065.

Pollitz, F.F., Bürgmann, R., Segall, P., 1998. Joint estimation of afterslip rate and postseismic relaxation following the 1989 Loma Prieta earthquake. Journal of Geophysical Research: Solid Earth 103, 26975-26992. doi:10.1029/98JB01554. 
Ragon, T., Sladen, A., Bletery, Q., Vergnolle, M., Cavalié, O., Avallone, A., Balestra, J., Delouis, B., 2019a. Joint Inversion of Coseismic and Early Postseismic Slip to Optimize the Information Content in Geodetic Data: Application to the 2009 Mw6.3 L'Aquila Earthquake, Central Italy. Journal of Geophysical Research: Solid Earth doi:10.1029/2018JB017053.

Ragon, T., Sladen, A., Simons, M., 2018. Accounting for uncertain fault geometry in earthquake source inversions - I: theory and simplified application. Geophysical Journal International 214, 1174-1190. doi:10.1093/gji/ggy187.

Ragon, T., Sladen, A., Simons, M., 2019b. Accounting for uncertain fault geometry in earthquake source inversions - II: Application to the Mw 6.2 Amatrice earthquake, Central Italy. Geophysical Journal International doi:10.1093/gji/ggz180.

Ruegg, J.C., Rudloff, A., Vigny, C., Madariaga, R., de Chabalier, J.B., Campos, J., Kausel, E., Barrientos, S., Dimitrov, D., 2009. Interseismic strain accumulation measured by GPS in the seismic gap between Constitución and Concepción in Chile. Physics of the Earth and Planetary Interiors 175, 78-85. doi:10.1016/j.pepi.2008.02.015.

Ruiz, S., Madariaga, R., Astroza, M., Saragoni, G.R., Lancieri, M., Vigny, C., Campos, J., 2012. Short-Period Rupture Process of the 2010 Mw 8.8 Maule Earthquake in Chile. Earthquake Spectra 28, S1-S18. doi:10.1193/1.4000039.

Sladen, A., Trevisan, J., 2018. Shallow megathrust earthquake ruptures betrayed by their outertrench aftershocks signature. Earth and Planetary Science Letters 483, 105-113.

Steketee, J., 1958. On volterra's dislocations in a semi-infinite elastic medium. Canadian Journal of Physics 36, 192-205.

Stevens, V.L., Avouac, J.P., 2015. Interseismic coupling on the main Himalayan thrust. Geophysical Research Letters 42, 5828-5837. doi:10.1002/2015GL064845.

Tinti, S., Armigliato, A., 2002. A 2-D hybrid technique to model the effect of topography on coseismic displacements. Application to the Umbria-Marche (central Italy) 1997 earthquake sequence. Geophysical Journal International 150, 542-557. doi:10.1046/j.1365-246X. 2002. 01721.x.

Tong, X., Sandwell, D., Luttrell, K., Brooks, B., Bevis, M., Shimada, M., Foster, J., Smalley, R., Parra, H., Soto, J.C.B., Blanco, M., Kendrick, E., Genrich, J., Caccamise, D.J., 2010. The 2010 Maule, Chile earthquake: Downdip rupture limit revealed by space geodesy. Geophysical Research Letters 37. doi:10.1029/2010GL045805. 
Trasatti, E., Kyriakopoulos, C., Chini, M., 2011. Finite element inversion of DInSAR data from the $\mathrm{Mw}$ 6.3 L'Aquila earthquake, 2009 (Italy). Geophysical Research Letters 38. URL: https://agupubs.onlinelibrary.wiley.com/doi/abs/10.1029/2011GL046714, doi:10.1029/2011GL046714.

Tsai, V.C., Ampuero, J.P., Kanamori, H., Stevenson, D.J., 2013. Estimating the effect of Earth elasticity and variable water density on tsunami speeds. Geophysical Research Letters 40, 492 496. doi:10.1002/grl.50147.

Tung, S., Masterlark, T., 2016. Coseismic slip distribution of the 2015 Mw7.8 Gorkha, Nepal, earthquake from joint inversion of GPS and InSAR data for slip within a 3-D heterogeneous domain. Journal of Geophysical Research: Solid Earth 121, 3479-3503. URL: https : / /agupubs . onlinelibrary.wiley.com/doi/abs/10.1002/2015JB012497, doi:10.1002/2015JB012497.

Twardzik, C., Vergnolle, M., Sladen, A., Avallone, A., 2019. Unravelling the contribution of early postseismic deformation using sub-daily GNSS positioning. Scientific Reports 9, 1775. doi:10.1038/s41598-019-39038-z.

Vigny, C., Socquet, A., Peyrat, S., Ruegg, J.C., Métois, M., Madariaga, R., Morvan, S., Lancieri, M., Lacassin, R., Campos, J., Carrizo, D., Bejar-Pizarro, M., Barrientos, S., Armijo, R., Aranda, C., Valderas-Bermejo, M.C., Ortega, I., Bondoux, F., Baize, S., Lyon-Caen, H., Pavez, A., Vilotte, J.P., Bevis, M., Brooks, B., Smalley, R., Parra, H., Baez, J.C., Blanco, M., Cimbaro, S., Kendrick, E., 2011. The 2010 Mw 8.8 Maule Megathrust Earthquake of Central Chile, Monitored by GPS. Science 332, 1417-1421. doi:10.1126/science.1204132.

Wang, K., Fialko, Y., 2015. Slip model of the 2015 Mw 7.8 Gorkha (Nepal) earthquake from inversions of ALOS-2 and GPS data. Geophysical Research Letters 42, 7452-7458. URL: https://agupubs.onlinelibrary. wiley.com/doi/abs/10.1002/2015GL065201, doi:10.1002/2015GL065201, arXiv:https://agupubs. onlinelibrary.wiley.com/doi/pdf/10.1002/2015GL065201.

Wang, K., Fialko, Y., 2018. Observations and modeling of coseismic and postseismic deformation due to the $2015 \mathrm{Mw} 7.8$ Gorkha (Nepal) earthquake. Journal of Geophysical Research: Solid Earth 123, 761-779. URL: https://agupubs . onlinelibrary.wiley.com/doi/abs/10.1002/2017JB014620, doi:10.1002/2017JB014620, arXiv:https://agupubs. onlinelibrary.wiley.com/doi/pdf/10.1002/2017JB014620. 
Wang, X., Wei, S., Wu, W., 2017. Double-ramp on the Main Himalayan Thrust revealed by broadband waveform modeling of the 2015 Gorkha earthquake sequence. Earth and Planetary Science Letters 473, 83-93. URL: http://www.sciencedirect.com/science/article/pii/ S0012821X1730300X.

Watada, S., Kusumoto, S., Satake, K., 2014. Traveltime delay and initial phase reversal of distant tsunamis coupled with the self-gravitating elastic Earth. Journal of Geophysical Research: Solid Earth 119, 4287-4310. doi:10.1002/2013JB010841.

Wessel, P., Luis, J.F., Uieda, L., Scharroo, R., Wobbe, F., Smith, W.H.F., Tian, D., 2019. The Generic Mapping Tools Version 6. Geochemistry, Geophysics, Geosystems n/a. doi:10.1029/ $2019 \mathrm{GC} 008515$.

Whipple, K.X., Shirzaei, M., Hodges, K.V., Ramon Arrowsmith, J., 2016. Active shortening within the Himalayan orogenic wedge implied by the 2015 Gorkha earthquake. Nature Geoscience 9, 711-716. URL: https://doi.org/10.1038/ngeo2797.

Williams, C.A., Wadge, G., 1998. The effects of topography on magma chamber deformation models: Application to Mt. Etna and radar interferometry. Geophysical Research Letters 25, 1549-1552. doi:10.1029/98GL01136.

Williams, C.A., Wadge, G., 2000. An accurate and efficient method for including the effects of topography in three-dimensional elastic models of ground deformation with applications to radar interferometry. Journal of Geophysical Research: Solid Earth 105, 8103-8120. URL: https://agupubs . onlinelibrary.wiley.com/doi/abs/10.1029/1999JB900307, doi:10.1029/1999JB900307, arXiv:https://agupubs.onlinelibrary.wiley.com/doi/pdf/10.1029/1999JB900307.

Williams, C.A., Wallace, L.M., 2018. The Impact of Realistic Elastic Properties on Inversions of Shallow Subduction Interface Slow Slip Events Using Seafloor Geodetic Data. Geophysical Research Letters 45, 7462-7470. doi:10.1029/2018GL078042.

Xue, L., Schwartz, S., Liu, Z., Feng, L., 2015. Interseismic megathrust coupling beneath the Nicoya Peninsula, Costa Rica, from the joint inversion of InSAR and GPS data. Journal of Geophysical Research: Solid Earth 120, 3707-3722. doi:10.1002/2014JB011844.

Yadav, R.K., Roy, P.N.S., Gupta, S.K., Khan, P.K., Catherine, J.K., Prajapati, S.K., Kumar, A., Puviarasan, N., Bhu, H., Devachandra, M., Malik, J., Kundu, B., Debbarma, C., Gahalaut, 
V.K., 2017. Rupture model of Mw 7.82015 Gorkha, Nepal earthquake: Constraints from GPS measurements of coseismic offsets. Journal of Asian Earth Sciences 133, 56-61. URL: http://www.sciencedirect.com/science/article/pii/S136791201630092X.

Zuo, R., Qu, C., Shan, X., Zhang, G., Song, X., 2016. Coseismic deformation fields and a fault slip model for the Mw7.8 mainshock and Mw7.3 aftershock of the Gorkha-Nepal 2015 earthquake derived from Sentinel-1A SAR interferometry. Tectonophysics 686, 158-169. URL: http://www . sciencedirect.com/science/article/pii/S0040195116303146. quake. Geophysical Research Letters 42, 6229-6235. URL: https://agupubs . onlinelibrary . wiley.com/doi/abs/10.1002/2015GL064995, doi:10.1002/2015GL064995.

Yang, Y., Chen, Q., Xu, Q., Liu, G., Hu, J.C., 2019. Source model and coulomb stress change of the $2015 \mathrm{Mw} 7.8$ Gorkha earthquake determined from improved inversion of geodetic surface deformation observations. Journal of Geodesy 93, 333-351. URL: https://doi.org/10.1007/ s00190-018-1164-9.

Yi, L., Xu, C., Zhang, X., Wen, Y., Jiang, G., Li, M., Wang, Y., 2017. Joint inversion of GPS, InSAR and teleseismic data sets for the rupture process of the 2015 Gorkha, Nepal, earthquake using a generalized ABIC method. Journal of Asian Earth Sciences 148, 121-130. URL: http: //www.sciencedirect.com/science/article/pii/S1367912017304601.

Yoshimoto, M., Watada, S., Fujii, Y., Satake, K., 2016. Source estimate and tsunami forecast from far-field deep-ocean tsunami waveforms-The 27 February $2010 \mathrm{Mw} 8.8$ Maule earthquake. Geophysical Research Letters 43, 659-665. doi:10.1002/2015GL067181.

Yue, H., Lay, T., Rivera, L., An, C., Vigny, C., Tong, X., Soto, J.C.B., 2014. Localized fault slip to the trench in the 2010 Maule, Chile $\mathrm{Mw}=8.8$ earthquake from joint inversion of high-rate GPS, teleseismic body waves, InSAR, campaign GPS, and tsunami observations. Journal of Geophysical Research: Solid Earth 119, 7786-7804. doi:10.1002/2014JB011340.

Zhao, S., Kaneda, Y., Müller, R.D., Takahashi, Y., 2004. 3-D finite-element modelling of deformation and stress associated with faulting: effect of inhomogeneous crustal structures. gji 157, 629-644. URL: https://dx.doi.org/10.1111/j.1365-246X.2004.02200.x. 


\section{Supplementary material for Impact of topography on earthquake static slip inversions}

\section{Contents}

1. Text S1: Data and forward model for the 2015 Gorkha earthquake

2. Figures S1 to S3: Data and forward model for the 2015 Gorkha earthquake

3. Text S2: Data and forward model for the 2010 Maule earthquake

4. Figures S4 to S8: Fit of the observations or synthetic dataset for the 2015 Gorkha earthquake

5. Figures S11 to S13: Other slip models and fit of the observations or synthetic dataset for the 2010 Maule earthquake

\section{S1. Data and forward model for the 2015 Gorkha event}

The Gorkha event has been well recorded by various types of geodetic data, such as static GPS offsets and synthetic aperture radar (InSAR).

In this study, we use the static GPS offsets processed and provided by Galetzka et al. (2015) and Yadav et al. (2017).

We also use three InSAR frames that are detailed in Table S1. The ALOS-2 data were collected by the Japan Aerospace Exploration Agency (JAXA) and processed by Lindsey et al. (2015). The Sentinel-1 data were collected by the European Space Agency and processed by Grandin et al. (2015). To improve computational efficiency, we resample InSAR observations based on model resolution (Lohman and Simons, 2005) with windows ranging from $30 \mathrm{~km}$ to $2 \mathrm{~km}$. We account for measurement uncertainties by building a data covariance matrix. To do so, we mask the area of coseismic displacement and estimate empirical covariograms as a function of distance between data points (Figure S1). Then, the InSAR covariance matrix $\mathbf{C}_{d}^{\text {insar }}$ is calculated from the best fitting exponential function to empirical covariograms (Jolivet et al., 2012). 


\begin{tabular}{lcc} 
Satellite (orbit pass) & Track & Interferogram pair \\
\hline ALOS 2 (ascending) & T157 & $02 / 21 / 2015-05 / 02 / 2015$ \\
ALOS 2 (descending) & T048 & $04 / 05 / 2015-05 / 03 / 2015$ \\
Sentinel 1A (ascending) & TN117 & $04 / 09 / 2015-05 / 03 / 2015$ \\
\hline
\end{tabular}

Table 1: Interferometric pairs used for the 2015 Gorkha event

\begin{tabular}{lc} 
Specifications & Values \\
\hline Domain coordinates & $83.5^{\circ} \mathrm{E} 87.5^{\circ} \mathrm{E} 26.6^{\circ} \mathrm{N} 29.2^{\circ} \mathrm{N}$ \\
Domain size & $390 \times 280 \times 83 \mathrm{~km}$ \\
Mesh spacing & $3 \mathrm{~km}$ \\
Number of elements & 323830 \\
Poisson's ratio & 0.25 \\
Young's modulus & $82.4 \mathrm{GPa}$ \\
\hline
\end{tabular}

Table 2: Model domain, mesh and material properties assumed for the Gorkha event.

\begin{tabular}{lc} 
Parameter & Values \\
\hline Length & $180 \mathrm{~km}$ \\
Width & $100 \mathrm{~km}$ \\
Number of subfaults along strike & 18 \\
Number of subfaults along dip & 10 \\
Strike & $285^{\circ}$ \\
Dip & $7^{\circ}$ \\
Northernmost point longitude & $86.118721^{\circ} \mathrm{E}$ \\
Northernmost point latitude & $27.280154^{\circ} \mathrm{N}$ \\
Depth of fault tip & $3.656 \mathrm{~km}$ \\
\hline
\end{tabular}

Table 3: Fault geometry parameters assumed for the Gorkha event. 


\section{S2. Figures S1 to S3: Data and forward model for the 2015 Gorkha earthquake}
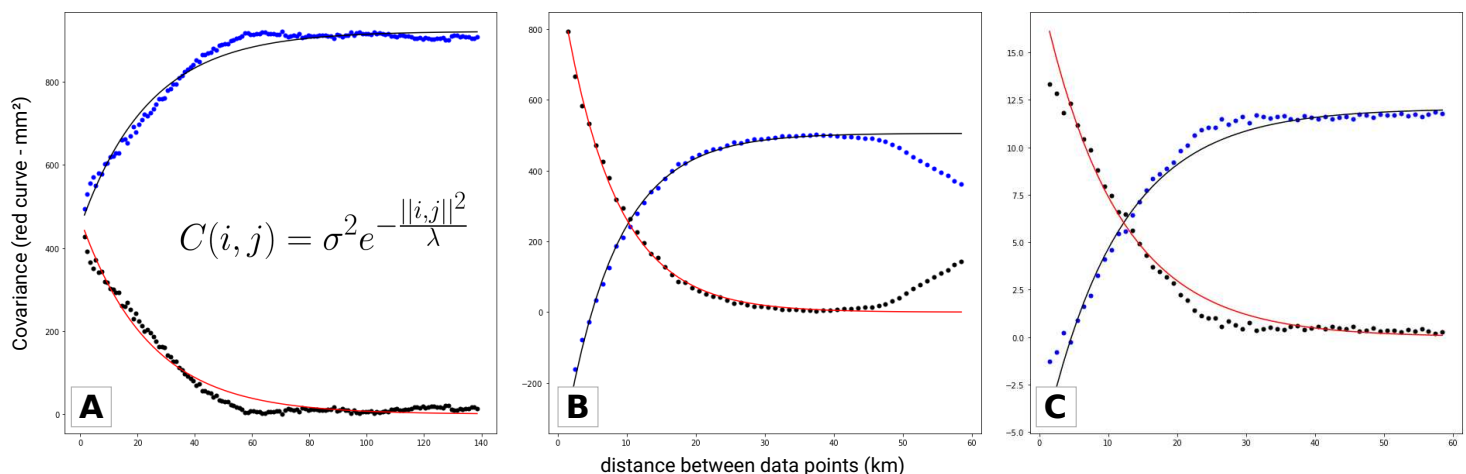

Figure S1: Empirical covariance functions for the interferograms used in the study of the Gorkha earthquake. Radially symmetric empirical covariance functions (black points) and associated best fit exponential functions (red curve) for the displacements derived from InSAR data. For each interferogram, we compute the empirical covariance as a function of the inter-pixel distance and then fit an exponential function (Jolivet et al. 2012). The exponential function is used to build the data covariance matrix. (A) for the ALOS2 T048 interferogram, with the exponential function characterized by $\lambda=0.2 \mathrm{~km}$ and $\sigma=427.4 \mathrm{~mm}$. (B) for the ALOS2 T157 interferogram, with $\lambda=7.65$ $\mathrm{km}$ and $\sigma=31.05 \mathrm{~mm}$. (C) for the Sentinel 1 interferogram, with $\lambda=10.94 \mathrm{~km}$ and $\sigma=4.29 \mathrm{~mm}$. 


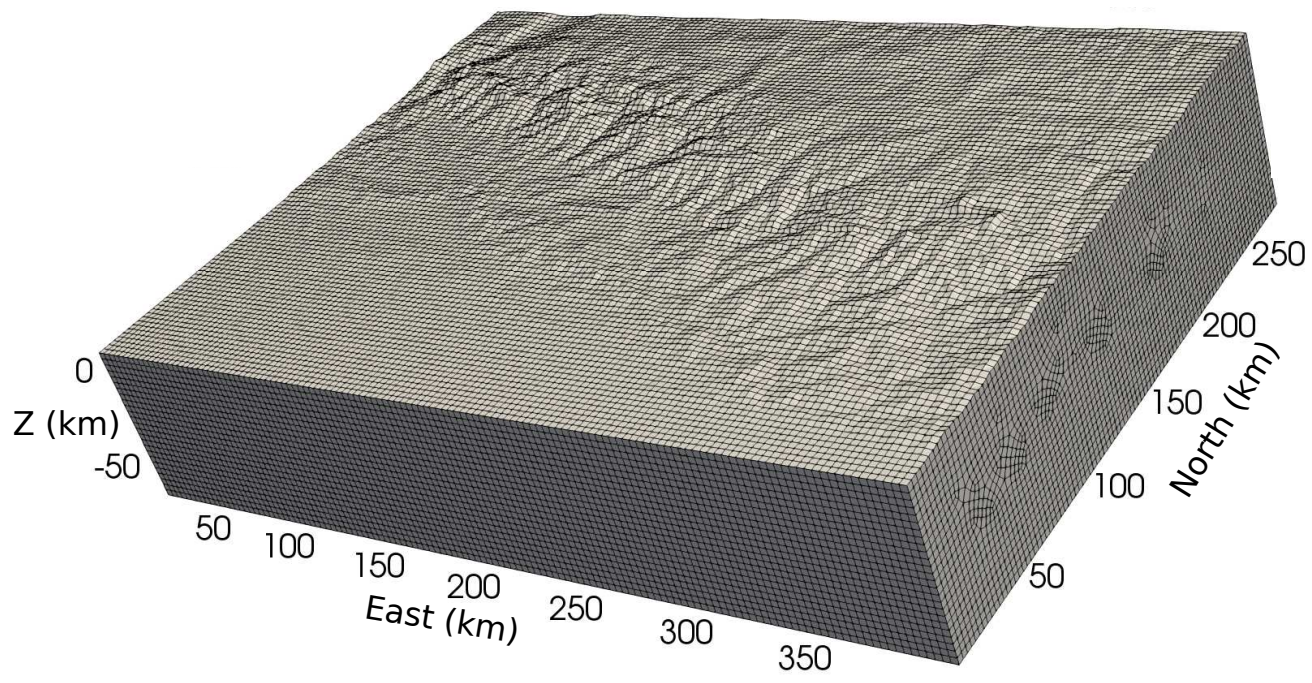

Figure S2: Topographic mesh used to calculate Green's functions with topography for the Gorkha event. This mesh was produced using Trelis 13.0 

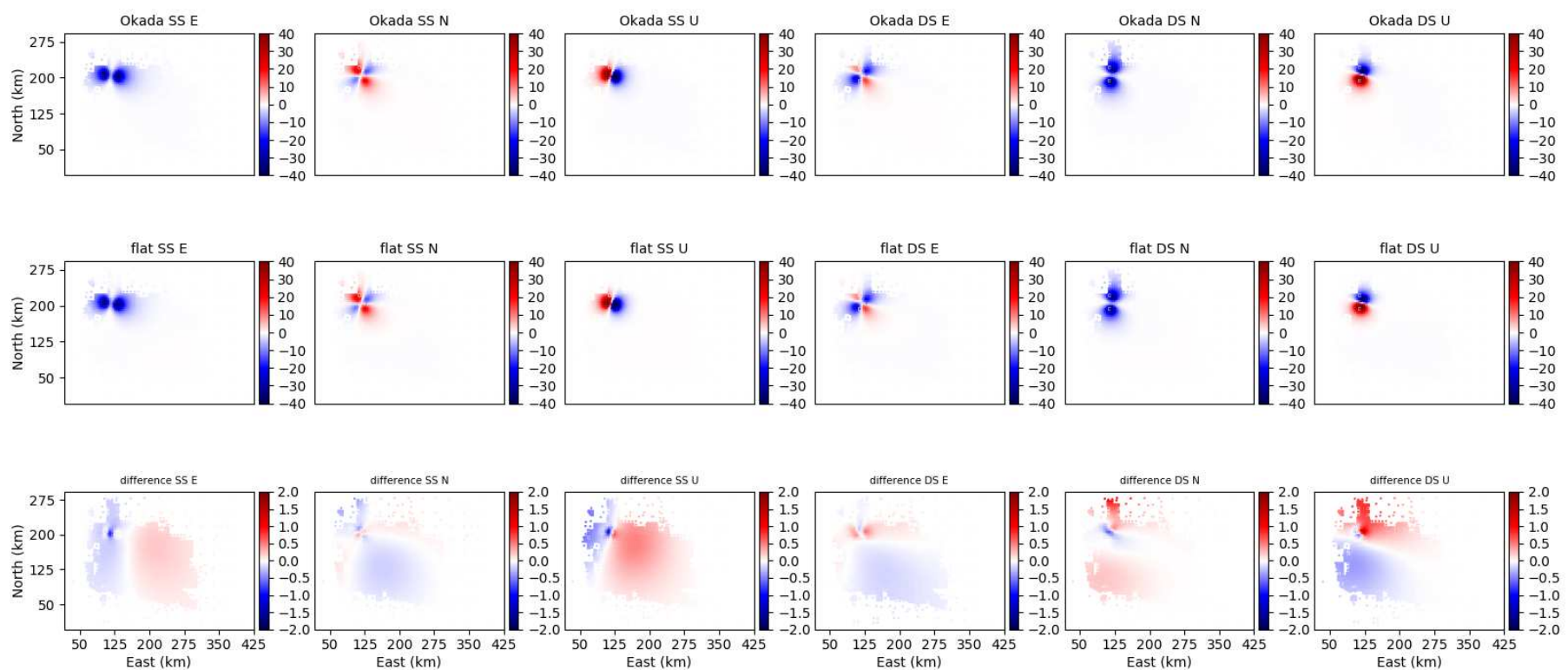

Figure S3: Benchmark for Gorkha Green's functions. The top row shows Green's functions calculated with Okada and the middle row shows Green's functions calculated using SPECFEM-X with a non-topographic mesh. The bottom row shows the difference, with color scale magnified by $20 \times$. Units of color bars are in millimeters. These differences are very small - not more than a few percent - so we can safely complare Okada Green's functions to SPECFEM-X 3D Green's functions. 
S3. Text S2: Data and forward model for the 2010 Maule event

\begin{tabular}{lc} 
Specifications & Values \\
\hline Domain coordinates & $-75.0^{\circ} \mathrm{E}-68.5^{\circ} \mathrm{E}-40.3^{\circ} \mathrm{N}-31.5^{\circ} \mathrm{N}$ \\
Domain size & $553 \times 958 \times 136 \mathrm{~km}$ \\
Mesh spacing & $6 \mathrm{~km}$ \\
Number of elements & 318400 \\
Poisson's ratio & 0.25 \\
Young's modulus & $100.0 \mathrm{GPa}$ \\
\hline
\end{tabular}

Table 4: Model domain, mesh and material properties assumed for the Maule event.

\begin{tabular}{lcc} 
Parameter & Values & \\
\hline Length & $570 \mathrm{~km}$ & \\
Width & $240 \mathrm{~km}$ & \\
Strike & $198^{\circ}$ \\
Dip & $18^{\circ}$ & \\
Northernmost point longitude & $-74.78718^{\circ} \mathrm{E}$ & \\
Northernmost point latitude & $-37.70672^{\circ} \mathrm{N}$ & \\
Depth of fault tip & $9.760 \mathrm{~km}$ & \\
& Near-trench row & Deeper rows \\
Number of subfaults along strike & 7 & 13 \\
Number of subfaults along dip & 1 & 8 \\
Subfault size (along dip - along strike) & $81.4 \times 48 \mathrm{~km}$ & $43.8 \times 24 \mathrm{~km}$ \\
\hline
\end{tabular}

Table 5: Fault geometry parameters assumed for the Maule event. 
S4. Figures S4 to S8: Fit of the observations or synthetic dataset for the 2015 Gorkha earthquake 

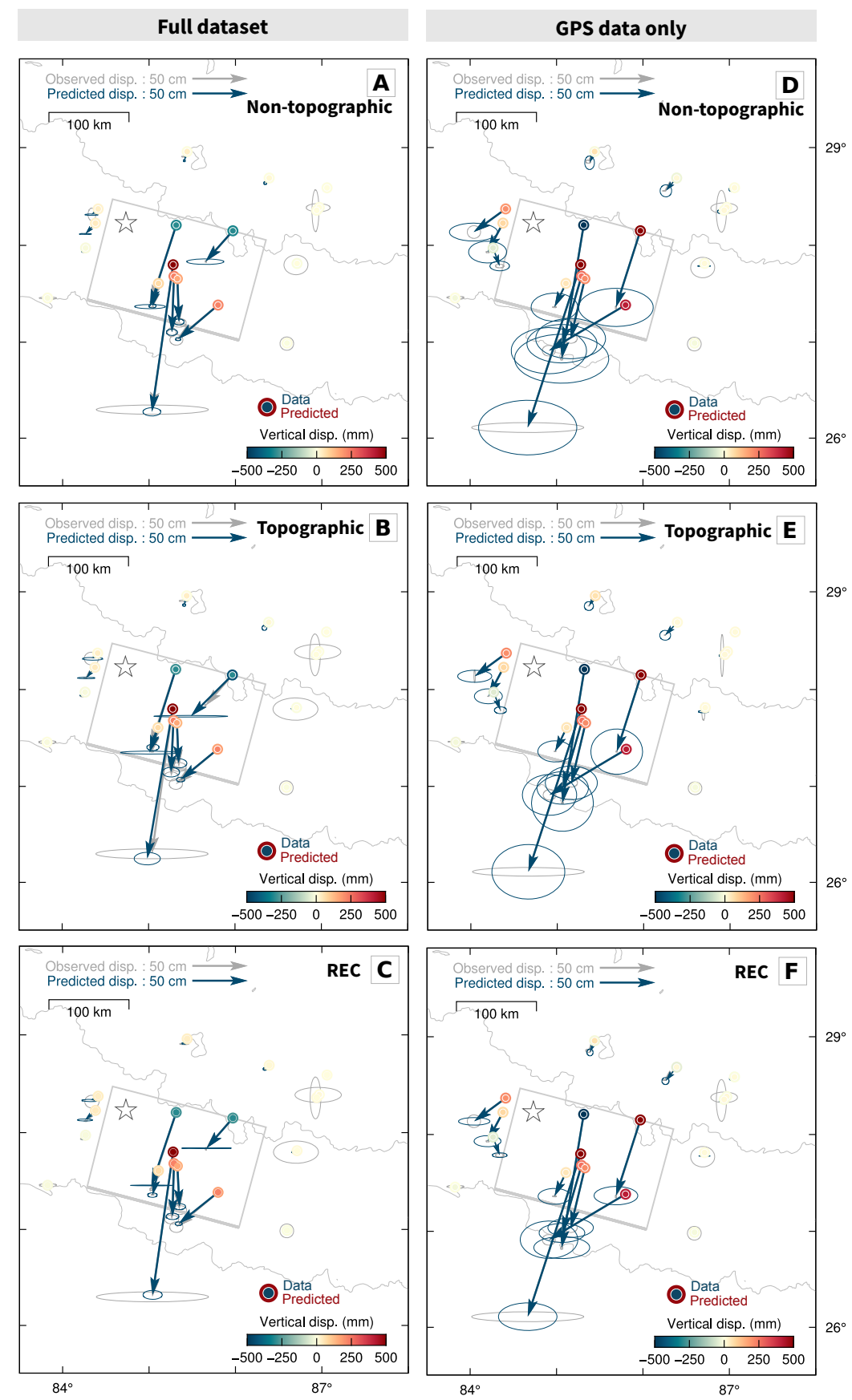

Figure S4: Synthetic (derived from the target slip models presented in Figure 3) and predicted GPS offsets for the 2015 Gorkha event, using either non-topographic (A, D), topographic (B, E) or REC Green's functions (C, F), and for inversions using either the full synthetic dataset (GPS and InSAR, left) or the synthetic GPS dataset only (right). Predictions are inferred from the average model. Observed horizontal surface displacements are in gray with $95 \%$ confidence ellipses, and predicted displacements are in blue with $95 \%$ confidence ellipses. Vertical displacements are color-coded with color-scale truncated at $(-1 \mathrm{~m}, 1 \mathrm{~m})$, the inner round shape representing the data and the outer circle representing the predicted displacements. The assumed fault geometry is shown with a gray rectangle, and the epicenter is the white star. 

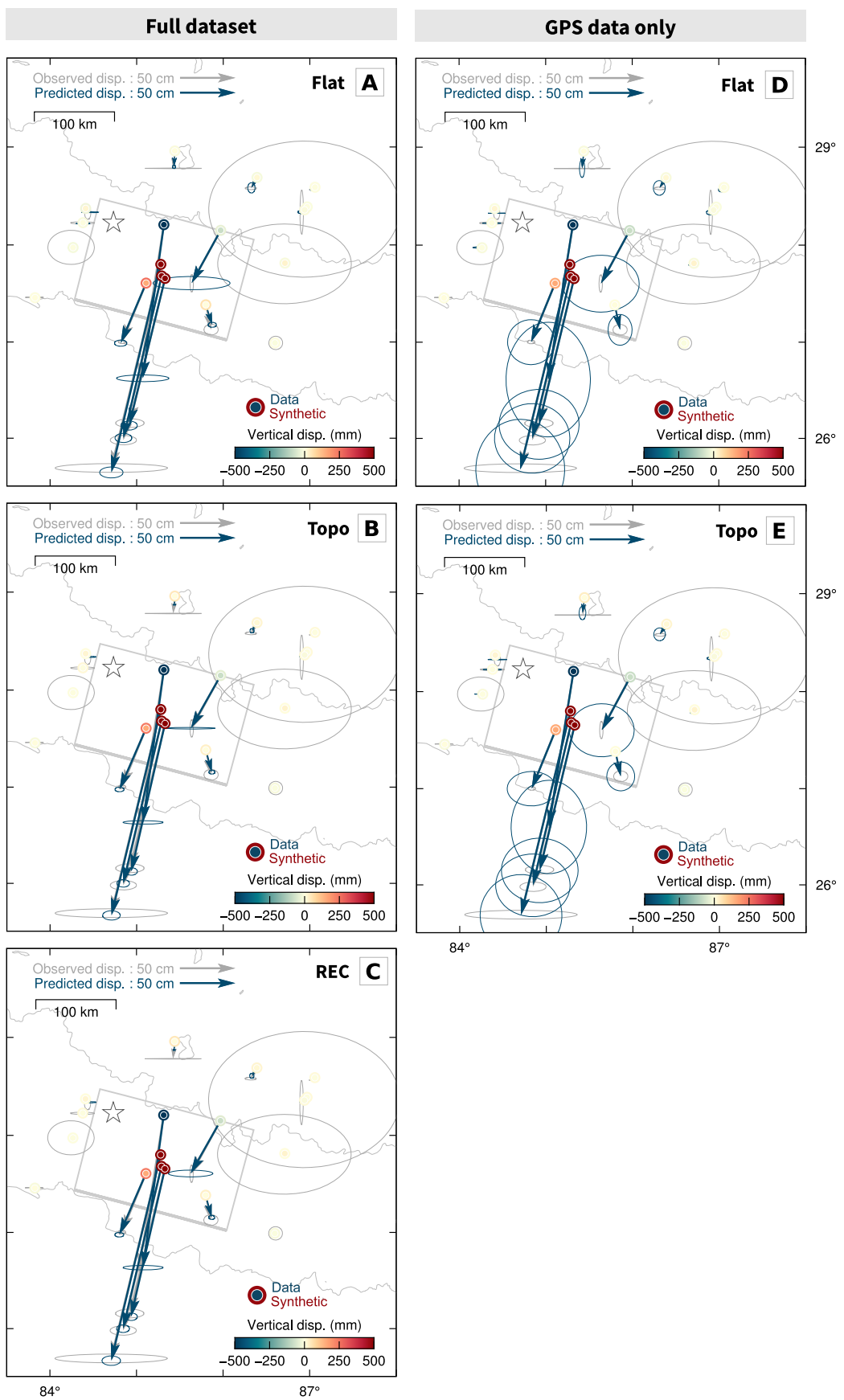

Figure S5: Observed and predicted GPS offsets for the 2015 Gorkha event, using either non-topographic (A, D), topographic (B,E) or REC Green's functions (C), and for inversions using either the full dataset (GPS and InSAR, left) or the GPS dataset only (right). Predictions are inferred from the average model. Observed horizontal surface displacements are in gray with $95 \%$ confidence ellipses, and predicted displacements are in blue with $95 \%$ confidence ellipses. Vertical displacements are color-coded with color-scale truncated at $(-1 \mathrm{~m}, 1 \mathrm{~m})$, the inner round shape representing the data and the outer circle representing the predicted displacements. The assumed fault geometry is shown with a gray rectangle, and the epicenter is the white star. 

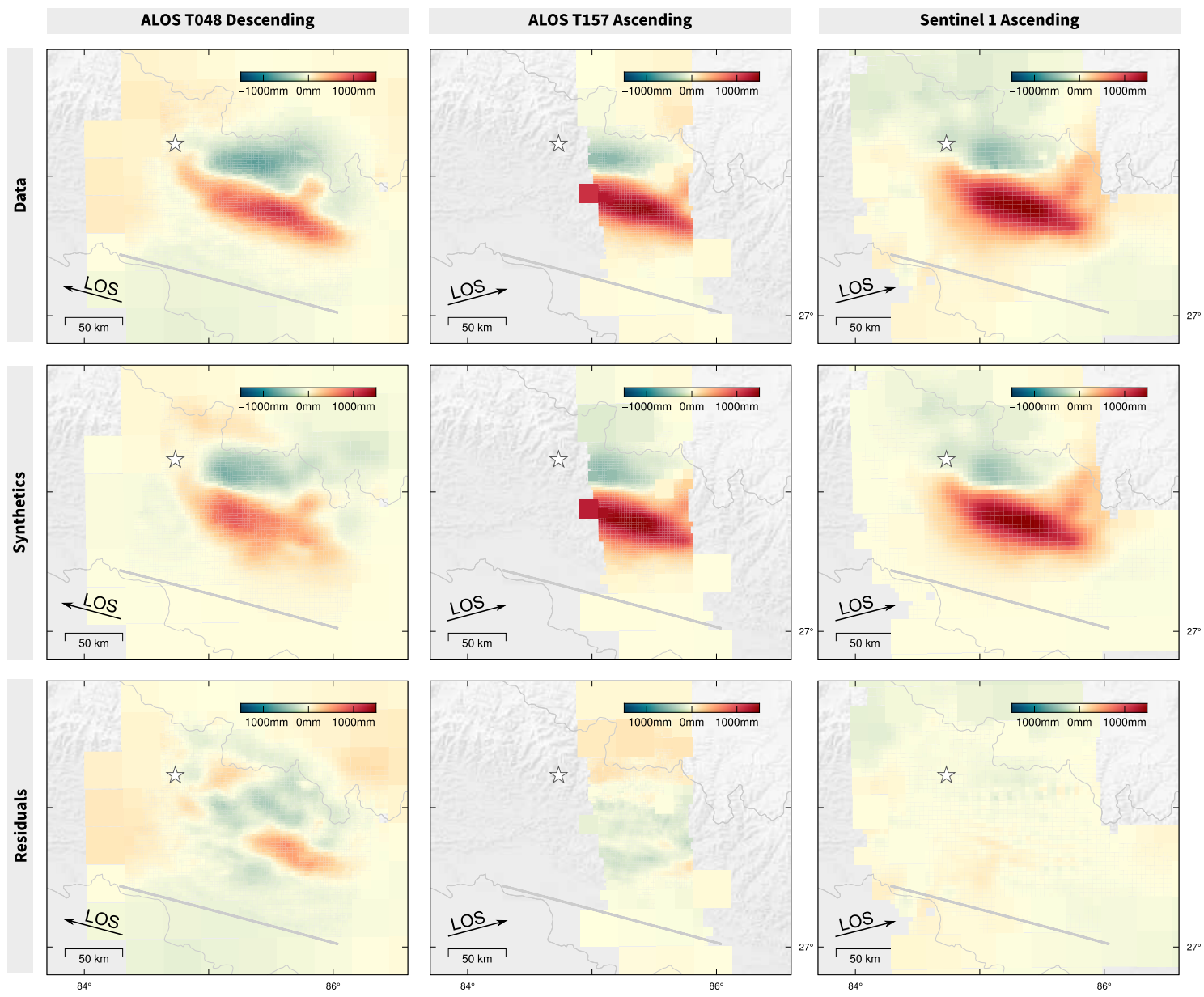

Figure S6: Fit of the InSAR dataset for the 2015 Gorkha event, using non-topographic Green's functions. Observed surface displacements in the LOS are shown in the top row, predicted ones in the middle row, and the residuals are shown in the lower row. Predictions are inferred from the average model. The assumed fault trace is shown with a dark gray line. 

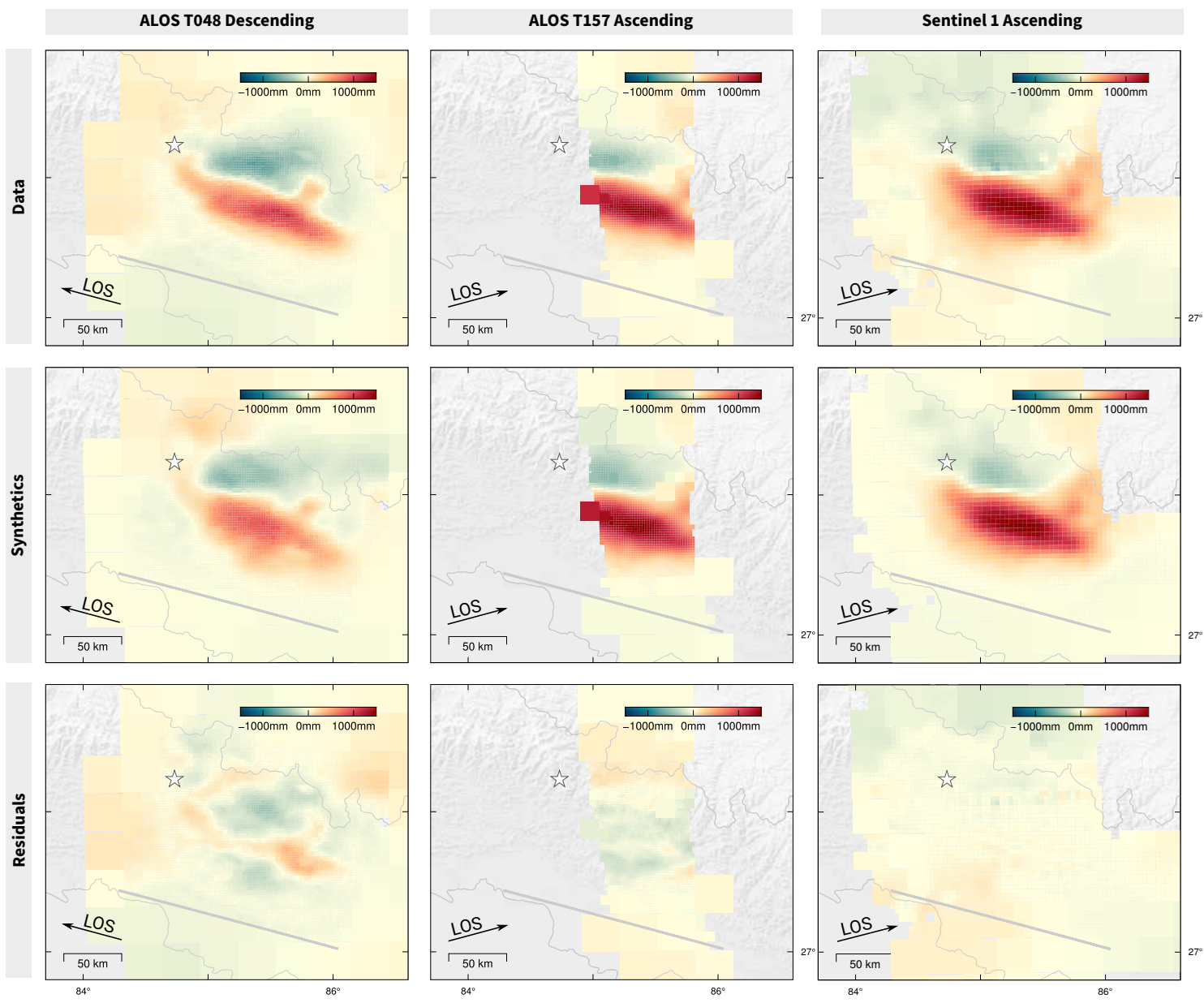

Figure S7: Fit of the InSAR dataset for the 2015 Gorkha event, using non-topographic Green's functions. Observed surface displacements in the LOS are shown in the top row, predicted ones in the middle row, and the residuals are shown in the lower row. Predictions are inferred from the average model. The assumed fault trace is shown with a dark gray line. 

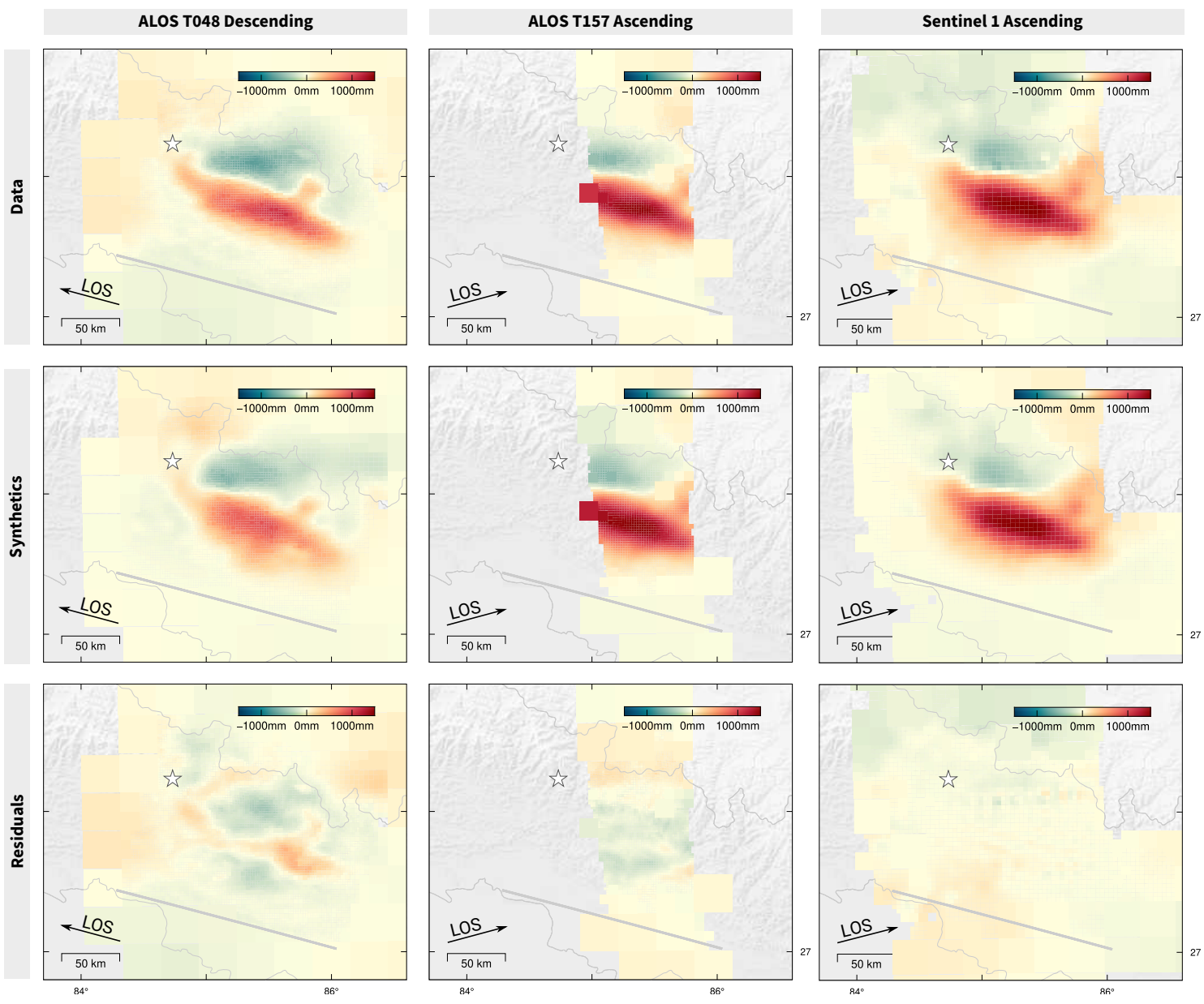

Figure S8: Fit of the InSAR dataset for the 2015 Gorkha event, using non-topographic Green's functions. Observed surface displacements in the LOS are shown in the top row, predicted ones in the middle row, and the residuals are shown in the lower row. Predictions are inferred from the average model. The assumed fault trace is shown with a dark gray line. 
S5. Figures S10 to S13: Other slip models and fit of the observations or synthetic dataset for the 2010 Maule earthquake

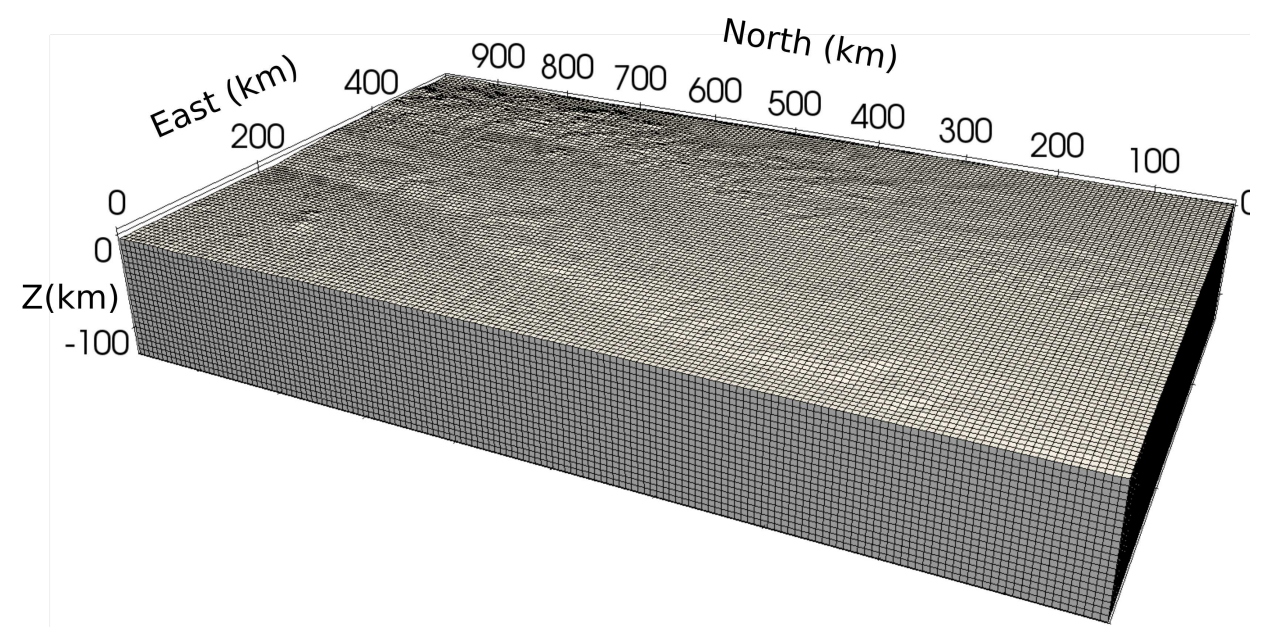

Figure S9: Topographic mesh used to calculate Green's functions with topography for the Maule event. This mesh was produced using Trelis 13.0 


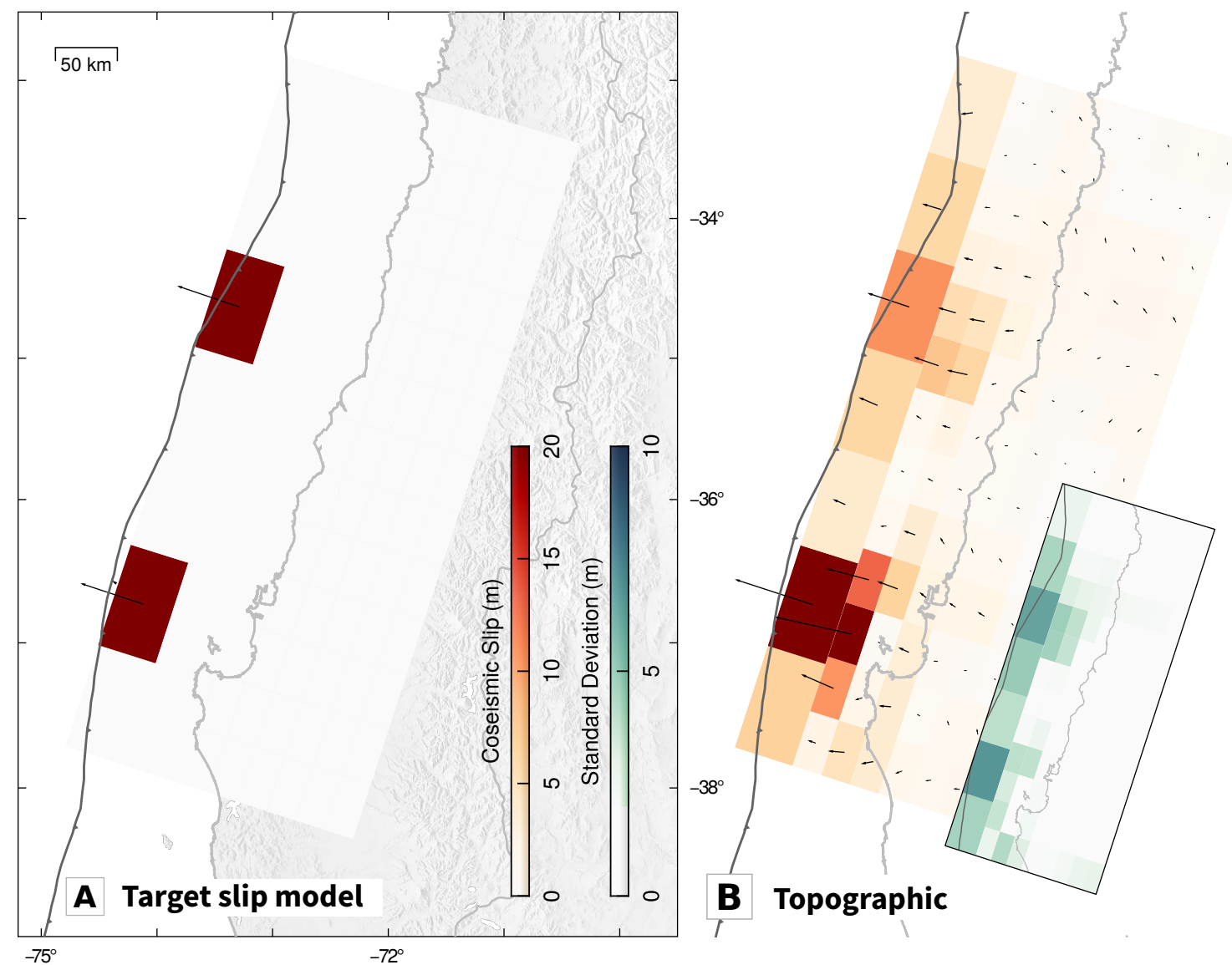

Figure S10: Slip model estimated from synthetic data for the Maule earthquake for a target model with only neartrench slip patches. (A) Target slip model used to calculate the synthetic data. (B) average slip amplitude (red color scale) and rake estimated with topographic Green's functions. Posterior standard deviation is shown in green at the bottom right of the slip model. 

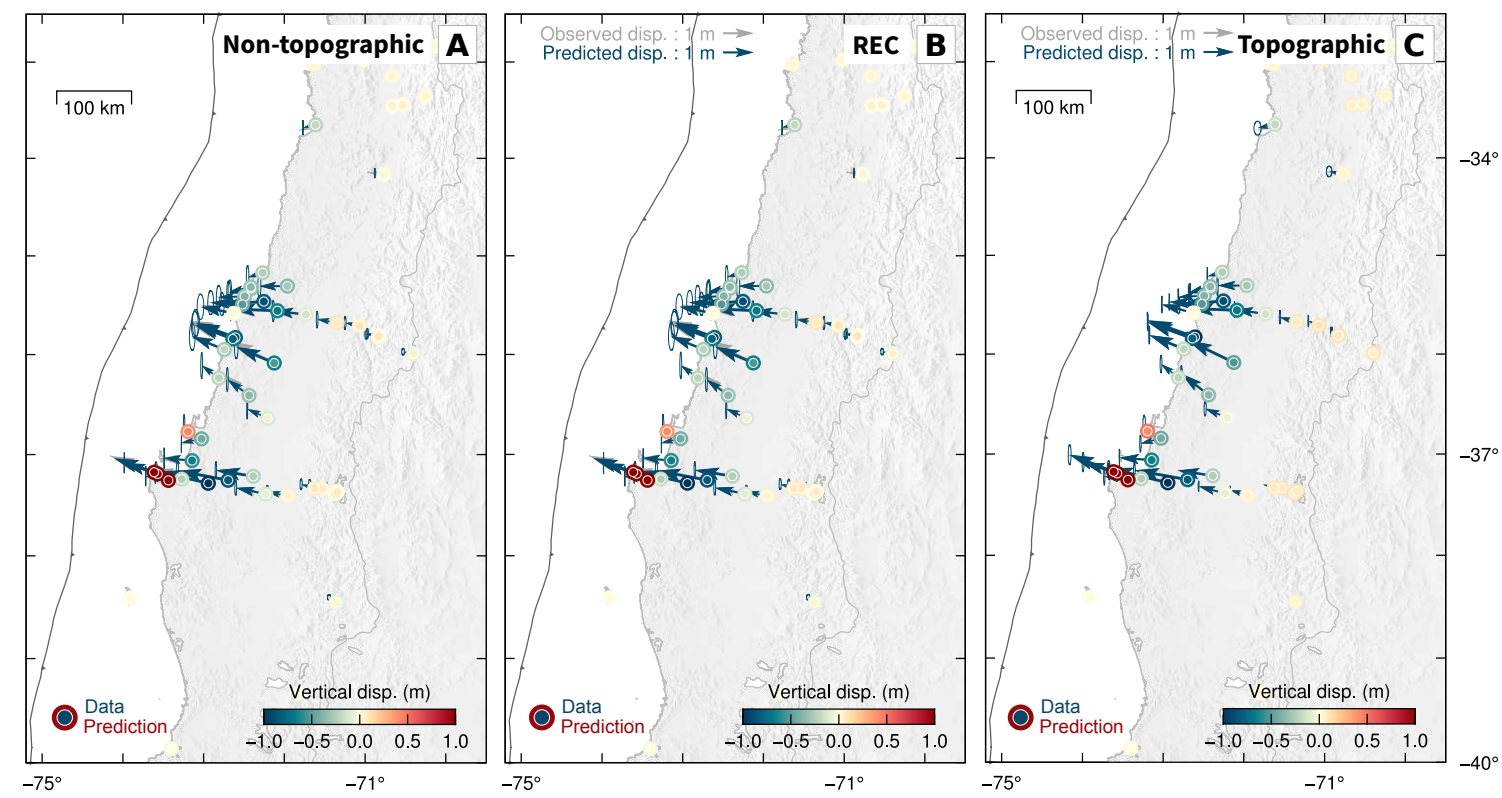

Figure S11: Synthetic (derived from the target slip model presented in Figure 7) and predicted GPS offsets for the 2010 Maule event, using either non-topographic (A), topographic (B) or REC Green's functions (C). Predictions are inferred from the average model. Observed horizontal surface displacements are in gray with $95 \%$ confidence ellipses, and predicted displacements are in blue with $95 \%$ confidence ellipses. Vertical displacements are color-coded with color-scale truncated at $(-1 \mathrm{~m}, 1 \mathrm{~m})$, the inner round shape representing the data and the outer circle representing the predicted displacements. 

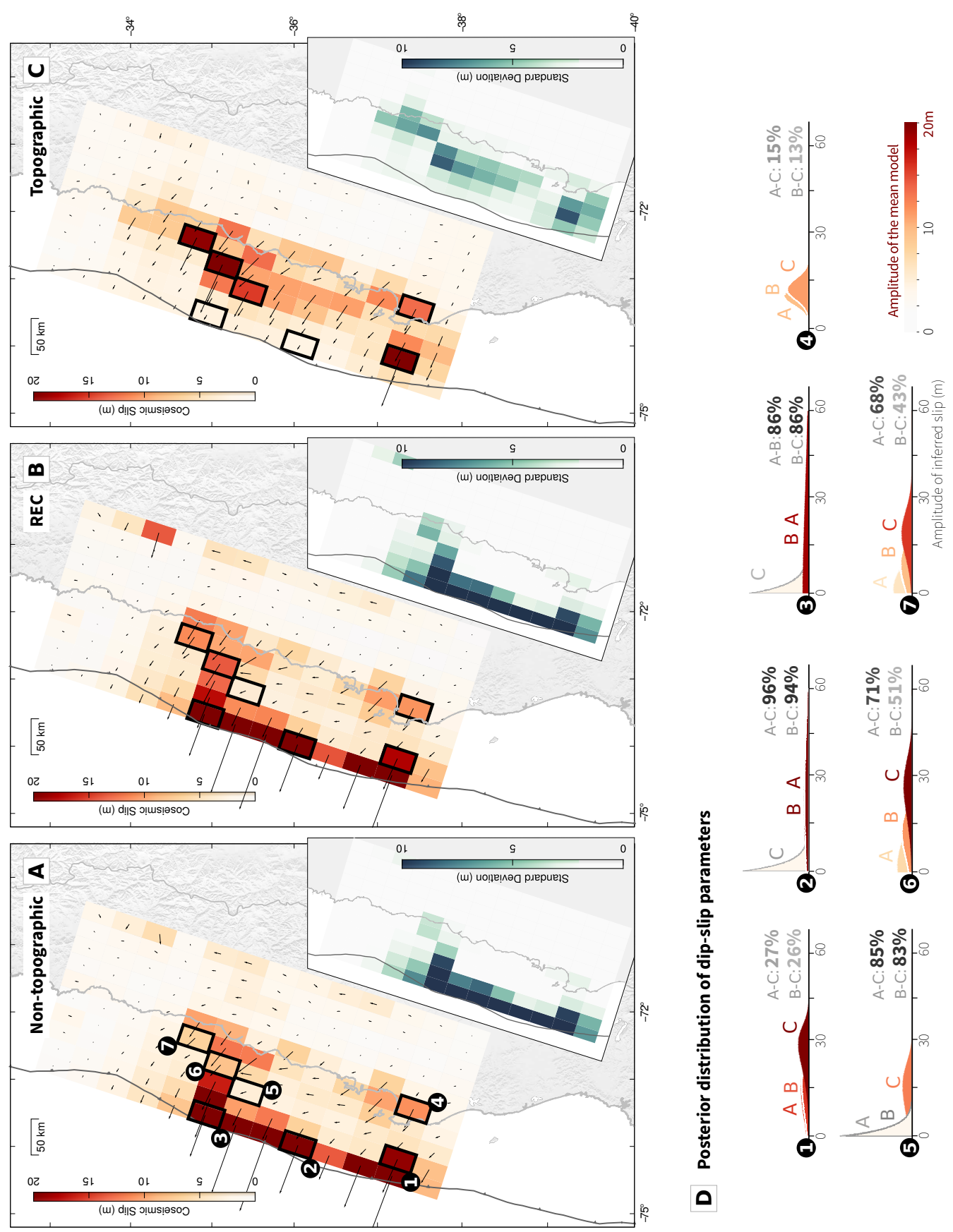

Figure S12: (A-C): Average slip models for the 2010 Maule event, assuming smaller subfaults at the trench, and either non-topographic (A), topographic (C) or corrected (B) GFs. The amplitude of the dip-slip and direction of the slip vector are shown in map view. A subfigure also indicates the standard deviation of every dip-slip model parameter in greenish color. In (D), the posterior distribution of some chosen dip-slip parameters is shown. 

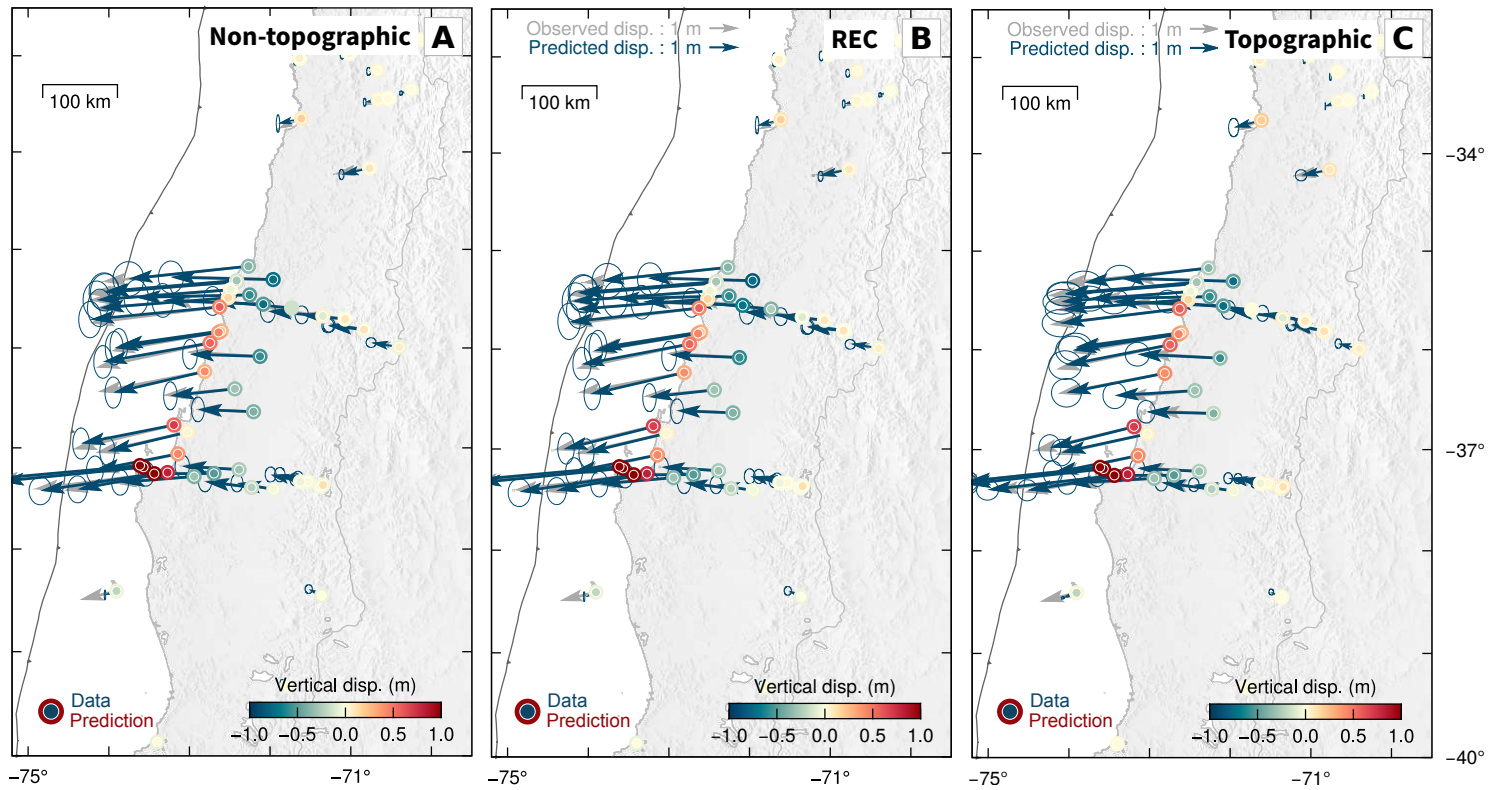

Figure S13: Observed and predicted GPS offsets for the 2010 Maule event, using either non-topographic (A), topographic (B) or REC Green's functions (C). Predictions are inferred from the average model. Observed horizontal surface displacements are in gray with $95 \%$ confidence ellipses, and predicted displacements are in blue with $95 \%$ confidence ellipses. Vertical displacements are color-coded with color-scale truncated at $(-1 \mathrm{~m}, 1 \mathrm{~m})$. the inner circle represents the data and the outer circle represents the predicted displacements. 


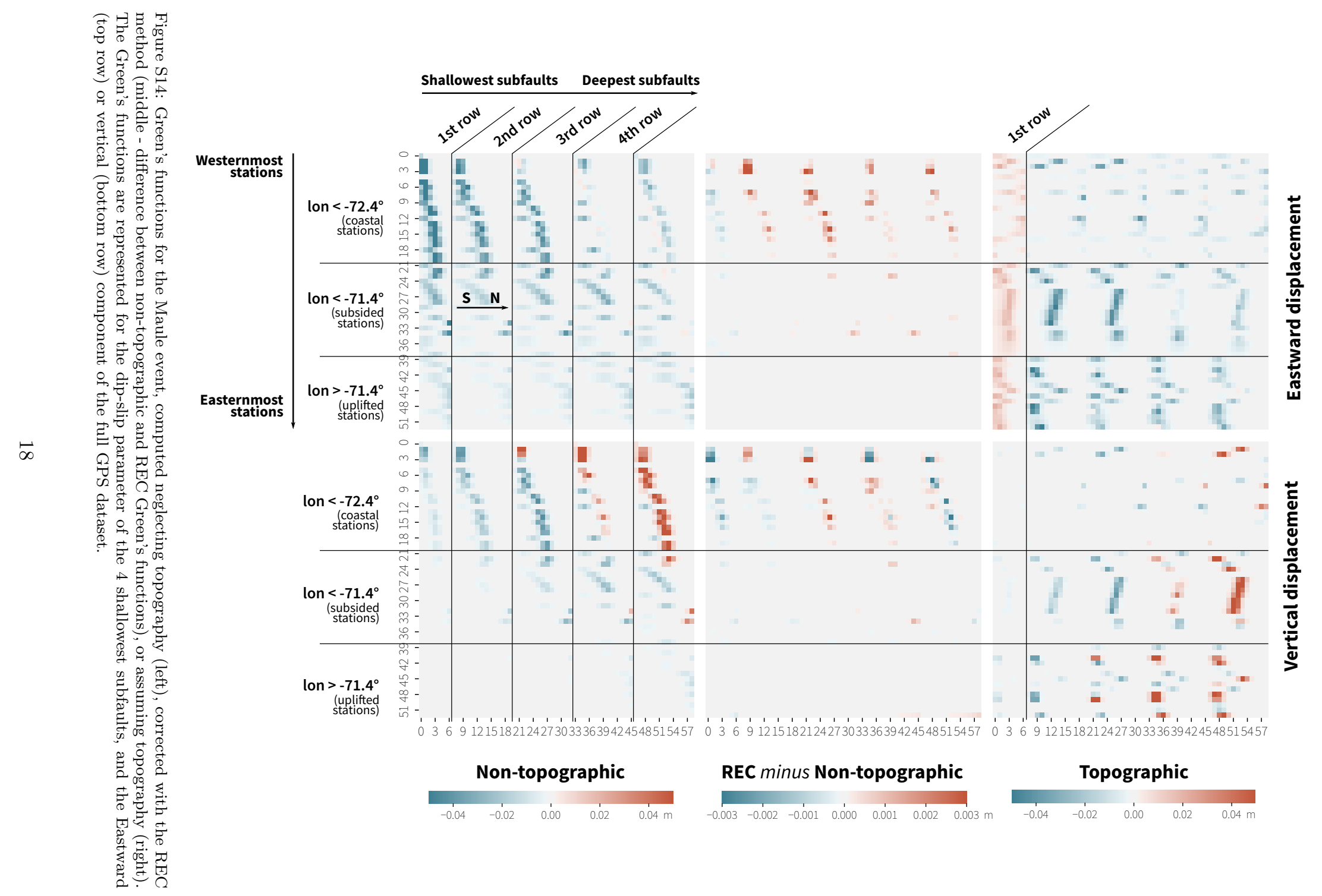




\section{References}

Galetzka, J., Melgar, D., Genrich, J.F., Geng, J., Owen, S., Lindsey, E.O., Xu, X., Bock, Y., Avouac, J.P., Adhikari, L.B., Upreti, B.N., Pratt-Sitaula, B., Bhattarai, T.N., Sitaula, B.P., Moore, A., Hudnut, K.W., Szeliga, W., Normandeau, J., Fend, M., Flouzat, M., Bollinger, L., Shrestha, P., Koirala, B., Gautam, U., Bhatterai, M., Gupta, R., Kandel, T., Timsina, C., Sapkota, S.N., Rajaure, S., Maharjan, N., 2015. Slip pulse and resonance of the Kathmandu basin during the 2015 Gorkha earthquake, Nepal. Science 349, 1091-1095. URL: https:// science.sciencemag.org/content/349/6252/1091, doi:10.1126/science. aac6383.

Grandin, R., Valle, M., Satriano, C., Lacassin, R., Klinger, Y., Simoes, M., Bollinger, L., 2015. Rupture process of the $\mathrm{Mw}=7.92015$ Gorkha earthquake (Nepal): Insights into Himalayan megathrust segmentation. Geophysical Research Letters 42, 8373-8382. doi:10.1002/ $2015 g 1066044$.

Jolivet, R., Lasserre, C., Doin, M.P., Guillaso, S., Peltzer, G., Dailu, R., Sun, J., Shen, Z.K., Xu, X., 2012. Shallow creep on the Haiyuan fault (Gansu, China) revealed by SAR interferometry. Journal of Geophysical Research: Solid Earth 117. URL: https://agupubs.onlinelibrary . wiley.com/doi/abs/10.1029/2011JB008732, doi:10.1029/2011JB008732.

Lindsey, E.O., Natsuaki, R., Xu, X., Shimada, M., Hashimoto, M., Melgar, D., Sandwell, D.T., 2015. Line-of-sight displacement from ALOS-2 interferometry: Mw 7.8 Gorkha earthquake and Mw 7.3 aftershock. Geophysical Research Letters 42,6655-6661. doi:10.1002/2015g1065385.

Lohman, R.B., Simons, M., 2005. Some thoughts on the use of InSAR data to constrain models of surface deformation: Noise structure and data downsampling. Geochemistry, Geophysics, Geosystems 6. URL: https://agupubs.onlinelibrary.wiley.com/doi/abs/10. 1029/2004GC000841, doi:10.1029/2004GC000841.

Yadav, R.K., Roy, P.N.S., Gupta, S.K., Khan, P.K., Catherine, J.K., Prajapati, S.K., Kumar, A., Puviarasan, N., Bhu, H., Devachandra, M., Malik, J., Kundu, B., Debbarma, C., Gahalaut, V.K., 2017. Rupture model of Mw 7.82015 Gorkha, Nepal earthquake: Constraints from GPS measurements of coseismic offsets. Journal of Asian Earth Sciences 133, 56-61. URL: http://www.sciencedirect.com/science/article/pii/S136791201630092X. 